\title{
Methods for the Prediction of Fatigue Delamination Growth in Composites and Adhesive Bonds - A Critical Review
}

\author{
J.A. Pascoe ${ }^{\mathrm{a}, *}$, R.C. Alderliesten ${ }^{\mathrm{a}}$, R. Benedictus ${ }^{\mathrm{a}}$ \\ ${ }^{a}$ Structural Integrity \& Composites Group, Faculty of Aerospace Engineering, Delft University of Technology, P.O. Box \\ 5058, 2600 GB Delft, The Netherlands
}

\begin{abstract}
An overview is given of the development of methods for the prediction of fatigue driven delamination growth over the past 40 years. Four categories of methods are identified: stress/strain-based models, fracture mechanics based models, cohesive-zone models, and models using the extended finite element method. It is highlighted that most models are phenomenological, based on the observed macro-scale behaviour of test specimens. It is suggested that a more physics based approach, focusing on elucidating the mechanisms involved, is needed to come to a full understanding of the problem of delamination growth.
\end{abstract}

Keywords: Delamination, Fatigue, Linear Elastic Fracture Mechanics, Cohesive Zone Model, XFEM

\section{NOTICE}

This is the author's version of a work that was accepted for publication in Engineering Fracture Mechanics. Changes resulting from the publishing process, such as, editing, corrections, structural formatting, and other quality control mechanisms may not be reflected in this document. Changes may have been made to this work since it was submitted for publication.

A definitive version was subsequently published in Engineering Fracture Mechanics, [112-113, pp. 72-96, (November 2013)]

DOI: http://dx.doi.org/10.1016/j.engfracmech.2013.10.003

\section{Introduction}

Over the past fifty years the quest to produce ever lighter structures has led to a greatly increased use of both composite materials and adhesive bonding. To ensure the safety of the resulting structures, it is imperative to understand their fatigue behaviour. Thus the rise of the application of composites and adhesive bonding has gone hand in hand with the development of fatigue models. Degrieck and Van Paepegem [1] classify these models into three major categories: fatigue life models, phenomenological models, and progressive damage models. In this classification fatigue life models are models that are not related to the actual degradation mechanisms, instead using S-N curves or similar means to predict the total fatigue life. Phenomenological models describe the gradual reduction of macroscopically observable properties, usually (residual) strength or stiffness. Progressive damage models predict the evolution of actual damage features, such as matrix cracks or delaminations.

Fatigue life and phenomenological models can be used to perform a safe-life assessment of a structure. However they can not be used to evaluate the effect of incidental damage sustained during service, or other kinds of effect-of-defect analysis. Furthermore, experience in metal structures has shown that a "slow growth"

\footnotetext{
* Corresponding author

Email address: j.a.pascoe@tudelft.nl (J.A. Pascoe)
} 


\begin{tabular}{|c|c|c|c|}
\hline \multicolumn{4}{|c|}{ Nomenclature } \\
\hline$A$ & Delamination area $\left(\mathrm{mm}^{2}\right)$ & $\Gamma$ & Mode-dependent toughness \\
\hline$a$ & Delamination length $(\mathrm{mm})$ & $\gamma$ & Mean stress sensitivity parameter \\
\hline$B$ & Width $(\mathrm{mm})$ & $\Delta G$ & Strain energy release rate range $\left(\mathrm{kJ} / \mathrm{m}^{2}\right.$, \\
\hline$C$ & Compliance $\left(\mathrm{mm}^{2} / \mathrm{N}\right)$ & & $\mathrm{N} / \mathrm{mm})$ \\
\hline$C$ & Fitting parameter & $\Delta K$ & Stress intensity factor range $(\mathrm{MPa} \sqrt{\mathrm{mm}})$ \\
\hline$D$ & Damage parameter & $\Delta \sigma$ & Stress range $(\mathrm{MPa})$ \\
\hline$d_{f, i}$ & Fatigue initiation damage parameter & $\delta$ & Displacement (mm) \\
\hline$f$ & Rule-of-mixtures weight factor & $\delta^{0}$ & Displacement at softening $(\mathrm{mm})$ \\
\hline$G$ & $\begin{array}{l}\text { Strain energy release rate }\left(\mathrm{kJ} / \mathrm{m}^{2} \text {, }\right. \\
\mathrm{N} / \mathrm{mm})\end{array}$ & $\delta^{f}$ & Displacement at failure (mm) \\
\hline$G_{\max }$ & $\begin{array}{l}\text { Strain energy release rate at maximum fa- } \\
\text { tigue load }\left(\mathrm{kJ} / \mathrm{m}^{2}, \mathrm{~N} / \mathrm{mm}\right)\end{array}$ & $\eta$ & Fitting parameter \\
\hline$G_{\min }$ & $\begin{array}{l}\text { Strain energy release rate at minimum fa- } \\
\text { tigue load }\left(\mathrm{kJ} / \mathrm{m}^{2}, \mathrm{~N} / \mathrm{mm}\right)\end{array}$ & $\begin{array}{l}\kappa \\
\lambda\end{array}$ & $\begin{array}{l}\text { Maximum displacement }(\mathrm{mm}) \\
\text { Critical SERR mode ratio }\end{array}$ \\
\hline$K$ & Stress intensity factor $(\mathrm{MPa} \sqrt{\mathrm{mm}})$ & $\lambda$ & Fitting parameter \\
\hline$K$ & Penalty stiffness in cohesive law $\left(\mathrm{N} / \mathrm{mm}^{3}\right)$ & $\sigma$ & Stress $(\mathrm{MPa})$ \\
\hline$m$ & Fitting parameter & $\tau$ & Shear stress $(\mathrm{MPa})$ \\
\hline$N$ & Number of cycles & $\phi$ & Potential \\
\hline$n$ & Fitting parameter & $\psi$ & Mode-mix angle (deg) \\
\hline$n$ & Number of divisions & \multicolumn{2}{|c|}{ Subscripts } \\
\hline$P$ & Load $(\mathrm{N})$ & $\mathrm{a}$ & Amplitude \\
\hline$Q$ & Activation Energy $(\mathrm{kJ} / \mathrm{mol})$ & c & Critical \\
\hline$R$ & Stress ratio & eff & Effective \\
\hline$R$ & Universal gas constant $(\mathrm{J} /(\mathrm{mol} \mathrm{K}))$ & eq & Equivalent \\
\hline$S$ & Stress (MPa) & I & Mode I \\
\hline $\begin{array}{l}T \\
T\end{array}$ & $\begin{array}{l}\text { Temperature (K) } \\
\text { Traction (MPa) }\end{array}$ & II & Mode II \\
\hline 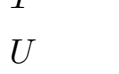 & Effective stress ratio & III & Mode III \\
\hline$w$ & Weight factor & $\mathrm{m}$ & Mean \\
\hline Greek & Symbols & $\max$ & Maximum \\
\hline$\alpha, \beta, \gamma$ & Fracture criterion exponents & $\min$ & Minimum \\
\hline$\beta$ & Mode-mix ratio & th & Threshold \\
\hline$\beta$ & Fitting parameter & tot & Total \\
\hline
\end{tabular}

philosophy will allow the design of lighter structures. In a slow growth philosophy, some growth of damage due to fatigue loading is accepted. A regular inspection schedule is used to ensure timely repair and thus safeguard the safety of the structure. By allowing damage growth, higher load levels are acceptable within 
the structure and a lighter weight design can be achieved. However, such an approach is only possible if the damage growth behaviour is sufficiently well understood to enable the planning of an inspection schedule that enables reliable detection of damage before it becomes critical. As a consequence, a slow growth philosophy requires a model from the category of progressive damage models.

The aim of this review is to provide an overview of the available progressive damage models for one specific type of damage: delamination. Delamination is one of the most common damage modes in composite materials, and is common to both composite materials and adhesive bonds. In adhesive bonding delamination is often referred to as disbonding. However if one considers a bonded joint to be a layered structure, it is clear that disbonding is a type of delamination. Indeed the mechanisms involved in both disbonding and delamination are highly similar, as are the prediction methods developed to deal with them. Thus in this review both models developed for disbonding of adhesive bonds and models developed for inter-laminar delamination of composites will be discussed. Over the past 40 years many models have been proposed to predict the growth of delaminations. This paper will chart their development and critically examine any shortcomings. Possible avenues for further research will also be identified.

When examining the literature on delamination growth an obstacle faced by the researcher is that delaminations can grow both due to quasi-static loads and due to cyclic loads. Growth due to cyclic loading generally occurs at maximum load levels that are lower than those required to cause growth under quasistatic loading. Although there is some fractographic evidence that the mechanisms involved are similar for brittle matrix materials (e.g. epoxy resins) [2-4], models for static delamination growth are generally not capable of predicting growth due to fatigue loading. Vice versa, fatigue growth models are generally not capable of predicting static delamination growth. It should also be noted that for tough matrix materials (e.g. thermoplastic resins such as PEEK) there is evidence that the mechanisms involved in static growth are not the same as those causing fatigue delamination growth [3]. Unfortunately many models in the literature are simply labelled as delamination growth models, without identifying whether they are applicable to static growth, fatigue growth or both. We therefore encourage future researchers to explicitly state whether their model is applicable to both static and fatigue growth or to only one of these cases. In this review we will consider fatigue delamination models. Static growth models will only be discussed in so far as they formed the basis for later fatigue models.

Many of the models in literature are variations on the same basic approach. To better emphasise the similarity between different models, whenever equations are quoted in this review, the symbols used by the original authors have been replaced by the notation as shown in the nomenclature table.

\section{Classification of the Methods for Prediction of Delamination Growth}

Many methods and models have been proposed for the prediction of delamination growth. They can be roughly grouped into four classes:

1. Stress/strain based methods. These relate the delamination growth to the stress or strain in the material.

2. Fracture mechanics based methods. These methods relate the delamination growth to a fracture mechanics property such as the stress intensity factor (SIF) or strain energy release rate (SERR). Usually these methods are based specifically on the sub-domain of linear elastic fracture mechanics (LEFM).

3. Cohesive zone models (CZMs). These are finite element method (FEM) based models in which the interface between two layers is modelled using cohesive zone elements. These elements do not have a constant stiffness, but instead incorporate a traction-displacement relation. A damage parameter is used to progressively reduce the stiffness of the element, simulating the growth of damage.

4. Extended finite element method (XFEM) based models. XFEM is a technique which allows discontinuities to exist within a finite element, rather than only at the boundaries, by using so-called enrichment functions. In this way, delaminations can be modelled at arbitrary points within the material, without first needing to define a crack path or crack plane. 
The stress/strain based methods are the oldest, one of the first having been developed in the late 1930s by Volkersen [5]. The fracture mechanics based methods were first proposed for use in delamination problems in the 1970s [6, 7], following their successful introduction to deal with fatigue crack growth in metals a decade earlier. The CZM approach is more recent, first having been used for delamination type problems in the late 1980s [8], though the concept itself is older. The XFEM approach is the most recent, having only been developed at the turn of this century [9]. Each of these classes will now be examined in turn.

\section{Stress/strain based methods}

Stress/strain based methods have long been used to determine the strength of adhesive bonds. Gleich [10] has provided a comprehensive review of the most important methods developed over the course of the $20^{\text {th }}$ century. The main problems studied in these investigations were the stress (and/or strain) distribution in the adhesive joint and the definition of suitable quasi-static failure criteria. Stress/strain based methods are generally most applicable to static delamination problems, though there are a few uses of stress/strain methods in fatigue investigations in the literature. Generally stress/strain methods are only used to find a fatigue life, and not predict delamination growth. This is comparable to the treatment of fatigue crack growth in metals, where the stress amplitude may be used to determine the fatigue life of a specimen. Fatigue crack growth on the other hand is predicted using the SIF [11].

Renton and Vinson [12] used a stress/strain method, but only considered the maximum stress for which a fixed fatigue life could be obtained. Liniecki et al. [13], Imanaka and Iwata [14, 15] and Ishii et al. [16] used the stress or stress amplitude to predict the fatigue life of a specimen. Although this information can be useful, these models do not provide any information on the delamination growth rate and thus cannot be used to predict the effect of defects. In addition, they cannot be used to support a slow growth design philosophy, for which an understanding of the delamination growth is imperative.

Only two models could be found in the literature where stress is used to predict delamination growth. One is that of Ratwani and Kan [17], the other is that of Poursartip and Chinatambi [18]. Ratwani and Kan suggested that delamination growth could be described by the following equation:

$$
\frac{d a}{d N}=C\left(\tau_{\max }-\tau_{\min }-\tau_{\mathrm{th}}\right)^{n} a^{m}
$$

where $d a / d N$ is the delamination growth rate, $\tau$ is the shear stress and $\tau_{\text {th }}$ is the threshold shear stress range below which delamination does not occur. This equation was successfully used to predict S-N curves for a number of specimens. Although equation 1 is written in terms of stress, note that $K=\sigma \sqrt{\pi a}$. Thus equation 1 is equivalent to using the stress intensity factor to correlate with delamination growth rate when $m=0.5 n$. Ratwani and Kan themselves state: "Assuming the delamination in the composite to behave like a crack, the power $m$ in [equation 1] may be taken as $0.5 n$ [17]".

Poursartip and Chinatambi [18] investigated the growth of delaminations from holes in a carbon fibre epoxy laminate and proposed the following, truly stress based, equation for the delamination growth rate:

$$
\frac{d a}{d N}=C\left(\frac{1+R}{1-R}\right)^{m}(\Delta \sigma)^{n}
$$

where $R$ is the stress ratio, $\Delta \sigma$ is the stress amplitude and $C, m$, and $n$ are fitting parameters, which are assumed to be material properties. Alternatively, this equation could be written as:

$$
\frac{d a}{d N}=2^{n} C\left(\frac{1+R}{1-R}\right)^{m-n} \sigma_{\text {mean }}^{n}
$$

which shows that the formulation of Poursartip and Chinatambi includes both the stress range and the mean stress as information on the stress cycle. Indeed the reason for choosing the form of equation 2 was to include the mean stress in the delamination growth relationship. 
Poursartip and Chinatambi also correlated the delamination growth rate with the SERR, making use of the relation [19]:

$$
G=\frac{P^{2}}{2 B} \frac{d C}{d a}
$$

where $G$ is the SERR, $P$ is the load, $B$ is the specimen width, and $C$ is the compliance. This allows equation 2 to be rewritten in terms of $\Delta G$, yielding:

$$
\frac{d a}{d N}=C\left(\frac{1+R}{1-R}\right)^{m}(\Delta G)^{n}
$$

Note that although this equation looks very similar to equation 2 , the values of $C, m$, and $n$ in equation 5 will be different. Poursartip and Chinatambi reported that they did not see much difference in goodness of fit between using $\Delta \sigma$ or $\Delta G$. As they themselves note, this is because in the specimen they used $d C / d a$ is constant and independent of the delamination length. In that case use of the SERR or the stress is indeed equivalent. However, this condition does not hold for all geometries.

To truly test whether it is more appropriate to use the SERR or the stress to predict delamination growth, one would have to conduct the comparison on a specimen where the compliance change is a function of delamination length. No such comparative studies could be found in the literature. Still, given the experience with fatigue crack growth in metals [11] one would expect that the stress by itself is not a sufficient similarity parameter to describe delamination growth.

\section{Fracture Mechanics Based Methods}

The fracture mechanics based methods link delamination growth to the fracture mechanics concepts of stress intensity factor (SIF) and strain energy release rate (SERR). It is important to note that these two parameters are equivalent and that using one rather than the other does not provide more or different information. The difficulties encountered in calculation of the SIF for inhomogeneous layered materials, such as fibre reinforced polymers (FRPs), have made the SERR the preferred parameter for the modelling of delamination growth. Depending on the specimen configuration the SERR may be calculated analytically, or finite element analysis (FEA) may be used. The most common finite element method to find the SERR is the virtual crack closure technique (VCCT) [20,21]. During experiments the SERR can relatively easily be obtained by measuring the change of compliance with crack length $(d C / d a)$. With equation 4 this can be used to calculate the SERR. This relative ease of measuring the SERR during experiments is another reason it is prefered as the fracture mechanics parameter.

The use of fracture mechanics for delamination problems derives from the success of Paris and co-workers in applying fracture mechanics to study fatigue crack growth in metals [22-24]. A concise overview of these early developments has recently been provided by Jones et al. [25].

In essence, most fracture mechanics methods for delamination growth are based on the Paris relation, written using the SERR, and modified to a greater or lesser extent. The basic form of this equation is [22-24]:

$$
\frac{d a}{d N}=C \Delta K^{n}
$$

where $C$ and $n$ are fitting parameters, of which the physical meaning is as yet unclear.

As dicussed above, and shown by Irwin [26] and Sih et al. [27], the SIF and the SERR are equivalent. Thus for delamination growth predictions equation 6 is usually rewritten in terms of the SERR. As yet there seems to be no consensus on whether to use $\Delta G$ (in analogy to $\Delta K$ in the originial equation ${ }^{1}$ ) or $G_{\max }$, as the basis of the equation. Thus the general form of the Paris equation underlying most fracture mechanics based delamination growth models is:

$$
\frac{d a}{d N}=C f(G)^{n}
$$

\footnotetext{
${ }^{1}$ This analogy is flawed, as is demonstrated in reference [28]
} 
It should be noted that equation 7 describes log-linear behaviour and thus only captures part of the delamination growth behaviour. As already noted by Mostovoy and Ripling [7], the delamination growth rate versus SERR curve has a sigmoidal shape. Figure 1 shows an example of a generalised growth rate versus SERR relation. Equation 7 only covers region II of this curve, although extentions to the model have been proposed in order to also include regions I and III.

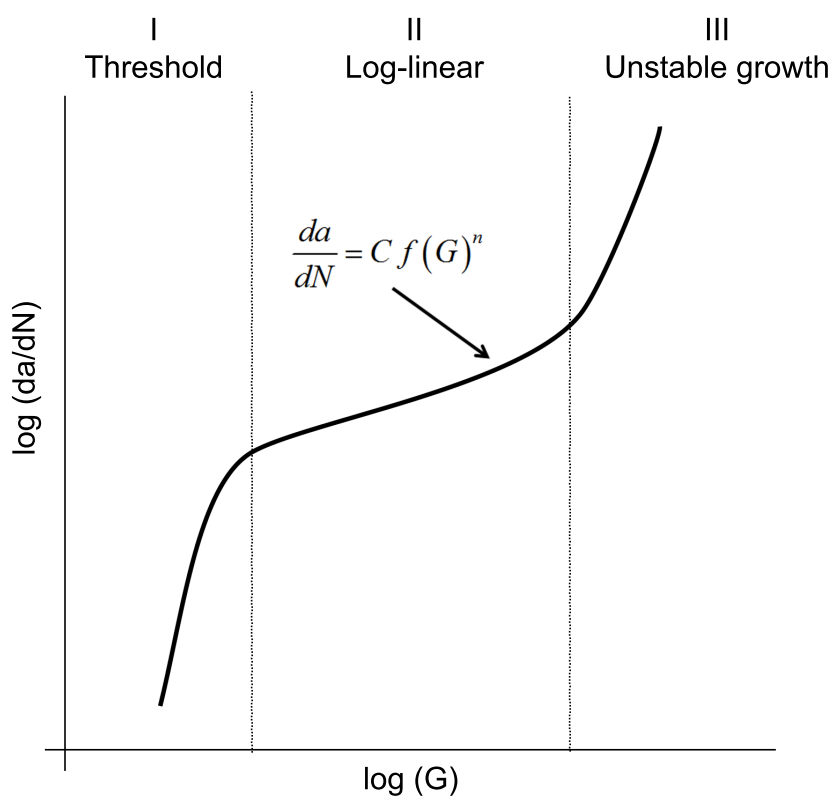

Figure 1: The sigmoidal behaviour of the delamination growth rate. Three regions can be observed. At low values of $G$ there is threshold or sub-critical behaviour (region I), at intermediate values the behaviour is log-linear (region II) and at high values unstable growth occurs, ultimately resulting in (quasi-)static failure (region III).

Modifications of equation 7 have been proposed in order to deal with a number of problems and effects, such as for example the loading mode-mix, the ' $R$-ratio effect', or the effect of crack closure. This section will first chart the early development of the fracture mechanics methods. Later developments will be discussed according to the specific problems or effects they were aimed to address.

\subsection{Early development}

The first to apply the Paris relation to fatigue delamination growth were Roderick et al. [6, 29], who studied what would now be called fibre metal laminates, and Mostovoy and Ripling [7], who worked on adhesively bonded joints. Roderick et al. explicitly referenced the work of Paris and Sih [30] to motivate their choice of equation 7 to correlate the delamination growth. Mostovoy and Ripling simply stated "...the methods used to define flaw tolerance to cyclic loading is [sic] patterned after that used for metals" [7].

Much early work on the fatigue delamination of adhesive bonds was performed at the NASA Langley Research Center [31-38]. Other contributions include those of Jablonski [39] and of Brussat and co-workers $[40,41]$. These works included the application of the Paris relation to various adhesive systems as well as early investigations of the effect of mode mixture, indicating that the total SERR provided a better correlation to the delamination growth rate than the individual mode SERR.

In fatigue delamination in fibre reinforced polymer (FRP) composites, the first to apply facture mechanics were Wang and Wang [42], who found a power-law relationship between the delamination growth and both the mode I and mode II SIF ranges, $\Delta K_{\mathrm{I}}$ and $\Delta K_{\mathrm{II}}$. O'Brien extended the work of Roderick et al., correlating delamination growth within FRP composites to the SERR [43, 44]. Early research into predicting fatigue 
delamination growth in FRP composites by means of fracture mechanics was also performed by Wilkins et al. [45] and Wang et al. [46] who also proposed a Paris type relationship.

It is notable that in all these early investigations, the use of the Paris relation to correlate the delamination growth rate was not motivated by a consideration of the physics of the delamination problem itself. Instead, a model of the form of equation 7 was chosen based on its earlier success in correlating fatigue crack growth in metals. Researchers initially cited the work of Paris and co-workers (e.g. [30]) or made a general reference to models used in metals. Later workers referred to initial investigations (e.g. [6, 7, 43, 45]) or general textbooks (e.g. [47]). Wang and Wang [42] are an exception in that they did not a priori propose a powerlaw relationship based on prior work. However they also did not motivate their choice of the SIF to correlate delamination growth, merely showing that a power-law correlation exists.

In the research that followed the investigations described in this section, equation 7 is usually taken as a given, with modifications being proposed to deal with a certain effect the investigators are studying.

Starting from these early investigations and running up to the present day, the SIF and SERR have undeniably been shown to correlate with delamination growth, as has been reported many times in literature. A question that is not answered by the literature however, is why this should be so. It is the authors' opinion that a better understanding of the underlying physics that prescribe the power-law relationship between SERR and delamination growth rate would help explain many effects that are observed to affect this relationship.

\section{2. $G_{\max }$ vs $\Delta G$ and the R-ratio effect}

No consensus has so far been reached on whether equation 7 should be a function of $G_{\max }$, or of $\Delta G$, i.e. the maximum SERR, or the SERR range. Many researchers pick either one or the other, often with a reference to earlier work from literature, without any comparison between the two options. Prominent examples can be found in the earliest published works on fatigue delamination, such as that of Roderick et al. [6], where $G_{\max }$ is used, and that of Mostovoy and Ripling [7], who used $\Delta G$.

In a later work Roderick et al. [29] did investigate which expression of $f(G)$ to use. Roderick et al. proposed three expressions for $G$; one based on using $\sigma_{\max }$, one based on using $\Delta \sigma$, and one based on the combination of both. Testing these expressions on three different material systems, they found that which expression correlated the delamination growth successfully depended on the material system, suggesting a difference in the sensitivity to the mean stress.

The first to use the $\Delta G$ formulation in FRP composites were Mohlin et al. [48], and Bathias and Laksimi [49]; they did not motivate their choice. Gustafson and Hojo [50] adopted $\Delta G$ based on models developed for metals [51] and rubber [52].

Both $G_{\max }$ and $\Delta G$ have successfully been correlated with delamination growth in a variety of investigations. Equation 7 with $f(G)=G_{\max }$ has been used to investigate the effect of laminate strengthening by interlayer strengthening [53-55] and through the thickness reinforcement [56, 57]. It has also been used to investigate growth in the presence of a hole [58] and post-impact [59]. Pradhan and Tay used $G_{\max }$ to investigate the evolution of the delamination shape [60]. Krueger used a $G_{\max }$ formulation to create a benchmark for FEM predictions of delamination growth [61-63].

$\Delta G$ has been used to correlate delamination growth in the case of high cycle $\left(>10^{8}\right.$ cycles) fatigue [6466] and to investigate the influence of the matrix [67-69]. It has also been used in the development of experimental procedures [70], and to investigate the effect of the stacking sequence [71, 72].

Regarding $\Delta G$ it should be noted that recently Rans et al. [28] have pointed out that in order to correctly apply the similarity principle the appropriate expression for $\Delta G$ is not $G_{\max }-G_{\min }$, but rather:

$$
\Delta G=\left(\sqrt{G_{\max }}-\sqrt{G_{\min }}\right)^{2}
$$

To avoid confusion this expression of the SERR range will be referred to as $\Delta \sqrt{G}$ in this paper. $\Delta \sqrt{G}$ had already been used in a number of works, such as those of Marissen [73], Zhao et al [74], Alderliesten [75], Alderliesten et al. [76], and Matsubara [77]. 
One reason little difference is seen between the use of $G_{\max }$ or $\Delta G$ is that the ratio $G_{\min } / G_{\max }$ is proportional to $R^{2}$. As noted by Wilkins et al. [45], this means that for example for $R=0.1, G_{\min } / G_{\max }=$ 0.01 and thus $G_{\max }$ and $\Delta G$ will be almost equal.

Only a few researchers have reported their considerations for choosing either $G_{\max }$ or $\Delta G$. Martin and Murri [78] and Aymerich et al. [56] selected $G_{\max }$ over $\Delta G$, because they claim facial interference during the unloading phase of the fatigue cycle ("consisting of fibre bridging, a plasticity zone wake, surface roughness, and debris"[79]) makes it difficult to correctly determine the value of $G_{\min }$. Note that this means Martin and Murri, and Aymerich et al. were contrasting the use of $G_{\max }$ with the use of an effective SERR range, as proposed by Jablonski [39], based on the crack closure concept discovered in metals by Elber [80]. In Jablonski's method instead of $\Delta G, \Delta G_{\text {eff }}$ is used, which is defined as:

$$
\Delta G_{\mathrm{eff}}=G_{\mathrm{max}}-G_{\text {closure }}
$$

where $G_{\text {closure }}$ is the SERR at the stress level for which crack closure occurs. In the more common definition of $\Delta G, G_{\min }$ is simply the SERR at the minimum applied stress level, which should not be difficult to determine and is not affected by facial interference.

Singh and Greenhalgh [81] stated that $G_{\max }$ was preferable due to the potential ambiguity in the definition of $\Delta G$ as $G_{\max }-G_{\min }$ in loading conditions where the stress changes sign (i.e. $R<0$ ), whereas $G$ will not. This argument is somewhat curious, as a given $G_{\max }$ value could correspond to many different loading conditions with values of $R<0$.

Furthermore Mall et al. [82], and Rezaizadeh and Mall [37] found that the use of $G_{\max }$ produced different curves for different $R$-ratios, whereas when they used $\Delta G$, the curves collapsed into a single line regardless of $R$-ratio. The observed disappearance of the $R$-ratio effect in this case may have been material dependant however, as other researchers have reported an $R$-ratio effect even when using $\Delta G[2,29]$.

Chan and Wang [83], using $G_{\max }$ normalised by the critical static SERR $G_{\mathrm{c}}$, also found an $R$-ratio dependency in their results and suggested that a modification of equation 7 was required to include this. This has recently been done by Allegri et al. [84], who proposed the relationship:

$$
\frac{d a}{d N}=C\left(\frac{G_{\text {IImax }}}{G_{\text {IIc }}}\right)^{\frac{n}{(1-R)^{2}}}
$$

The reason for choosing specifically this expression to include $R$ was not given, but the form suggests the line of reasoning followed was similar to that of Andersons et al. [85]. Andersons et al. used the Goodman relation to derive the exponent $n /(1-R)$ for a Paris-type relation based on the SIF, $K$. As $K_{\min } / K_{\max }$ is equal to $R$ and $G_{\min } / G_{\max }$ is equal to $R^{2}$, it seems Allegri et al. followed a similar approach.

Rans et al. [28] considered a number of datasets obtained from literature [73, 77, 86-89] As Rans et al. display data from several sources side by side in this paper, it can clearly be observed that there are large differences in the $R$-effect for different loading modes. Under mode I loading (based on data from [2]) the delamination growth rate for a given $\Delta G=G_{\max }-G_{\min }$ increases with increasing $R$, whereas for mode II (based on on data from [89]) the delamination growth rate for a given $\Delta G$ decreases with increasing $R$. When using the $\Delta \sqrt{G}$ formulation rather than $\Delta G$ the observed $R$-effect for mode II loading disappeared. For mode I an $R$-ratio effect was still observed.

Neither $G_{\max }$ nor $\Delta G$ or $\Delta \sqrt{G}$ seem to give a satisfactory resolution to the $R$-ratio effect. The authors contend that this is to be expected. Ultimately, delamination growth is driven by the fatigue load cycles applied to the structure. The use of fracture mechanics to predict the delamination growth rate is based on the similarity principle, i.e. the principle that if the SERR or SIF is equal for two delaminations, (whether in the same or different specimens), they are experiencing the same driving force and thus will have the same growth rate. However, using only the maximum stress, or only the stress range, is insufficient to properly characterise a stress cycle. To characterise a stress cycle one must always use two variables. Common parings include maximum and minimum stress $\left(S_{\max }, S_{\min }\right)$, mean stress and stress amplitude $\left(S_{\mathrm{m}}, S_{\mathrm{a}}\right)$, and stress range and $R$-ratio $(\Delta S, R)[11]$. 
Consider also that one can write:

$$
\begin{aligned}
G_{\max } & =\frac{2}{\left(1+R^{2}\right)} G_{\mathrm{m}} \\
\Delta G & =\frac{2\left(1-R^{2}\right)}{\left(1+R^{2}\right)} G_{\mathrm{m}}
\end{aligned}
$$

where $G_{\mathrm{m}}$ is the mean SERR. This shows that keeping $G_{\max }$ or $\Delta G$ constant and changing the $R$-ratio implies changing $G_{\mathrm{m}}$. Thus $G_{\max }$ and $\Delta G$ by themselves do not give sufficient information on the applied stress cycle to be able to fully characterise the delamination growth. One way of ensuring that full information on the stress cycle is used is by including the $R$-ratio in the equation as done by Poursartip and Chinatambi [18] (equation 2, using $G$ rather than $\sigma$ ), Andersons et al. [85], and Allegri et al. [84].

Another option is to describe the delamination growth rate in terms of both $G_{\max }$ and $\Delta \sqrt{G}$, or, equivalently, $K_{\max }$ and $\Delta K$. This has been proposed by Hojo et al. [2, 3], Atodaria et al. [90-92], Andersons et al. [88] and Jones et al. [25].

Hojo et al. [2, 3] proposed the following relationship:

$$
\frac{d a}{d N}=C \Delta K^{(1-\gamma) n} K_{\max }^{\gamma n}
$$

or equivalently (though the numerical values of $C, \gamma$ and $n$ will be different) [28]:

$$
\frac{d a}{d N}=C(\Delta \sqrt{G})^{2(1-\gamma) n} G_{\max }^{\gamma n}
$$

here $\gamma$ is an empirical material parameter that varies between 0 and 1 and represents the sensitivity to the mean (or equivalently, maximum) stress. Equation 13 was derived from the phenomenological observation that for a given delamination growth rate $\Delta K(1-R)^{\gamma}$ is constant, as first observed in metals by Klesnil and Lukáš [93]. In reference [2] delamination growth rates were plotted against $\Delta K$ for three different $R$-ratios. Plotting against $\Delta K_{\text {eq }}=\Delta K^{(1-\gamma) n} K_{\max }^{\gamma n}$ rather than $\Delta K$, these lines collapsed into one trend line for $d a / d N$ vs $\Delta K_{\text {eq }}$.

If a certain material has a high value of $\gamma$ this indicates that the fatigue delamination growth mechanism is largely controlled by the maximum stress, and thus is similar to the static growth mechanism. Conversely a low value of $\gamma$ indicates that the cyclic stress is more important for the fatigue growth mechanism, thus implying a different mechanism is dominant. This matches fractographic observations [2].

Atodaria et al. [90-92] proposed the similar set of equations:

$$
\begin{aligned}
\frac{d a}{d N} & =C\left(\Delta K^{1-\gamma} K_{\text {average }}^{\gamma}\right)^{n} \\
\frac{d a}{d N} & =C\left[(\sqrt{G})_{\text {average }}^{\gamma}(\Delta \sqrt{G})^{1-\gamma}\right]^{n}
\end{aligned}
$$

where $K_{\text {average }}$ and $\sqrt{G}$ average are weighted averages determined according to:

$$
\left[\frac{1}{n} \sum_{K_{\mathrm{th}}}^{K_{\max }} K^{w}\right]^{\frac{1}{w}},\left[\frac{1}{n} \sum_{\sqrt{G_{\mathrm{th}}}}^{\sqrt{G_{\max }}}(\sqrt{G})^{w}\right]^{\frac{1}{w}}
$$

where $n$ is the number of divisions by which the range $K_{\text {th }}$ to $K_{\max }$ is divided, and $w$ is an experimentally determined weight factor. No physical principle is invoked by Atodaria et al. or Hojo et al. to explain why $\Delta K$ and $K_{\text {average }}$ or $K_{\max }$ should be multiplied, rather than combined in some other way. For Hojo et al. the formulation of $\Delta K_{\text {eq }}$ follows from the phenomenological observation that $\Delta K(1-R)^{\gamma}$ is constant for a given delamination growth rate. Atodaria et al. chose multiplication due to the likewise phenomenological observation that for a fixed $K_{\max }$, the delamination growth rate decreases with increasing values of $R$ (due 
to the reduction of $\Delta K)$; whereas for a fixed $\Delta K$ the delamination growth rate increases with increasing $R$ ratio (due to the increase of $K_{\max }$ ). A mechanism based explanation of why multiplication is the appropriate form of combination unfortunately remains lacking.

Andersons et al. [88] propose the following equation for the delamination growth rate:

$$
\frac{d a}{d N}=C\left(\frac{\Delta K-\Delta K_{\mathrm{th}}}{K_{\mathrm{c}}-K_{\mathrm{m}}}\right)^{n}
$$

with

$$
\Delta K_{\mathrm{th}}=\Delta K_{\mathrm{th} 0}(1-R)^{\gamma}
$$

where $\gamma$ is the mean stress sensitivity parameter defined by Hojo et al., and $\Delta K_{\text {tho }}$ is the value of $\Delta K_{\text {th }}$ extrapolated to $R=0$. Jones et al. [25] note that this formulation is similar to the Hartman-Schijve equation proposed for metals [94]. Jones et al. then formulate equations for mode I and II delamination growth as:

$$
\frac{d a}{d N}=C\left(\frac{\Delta \sqrt{G_{\mathrm{I}}}-\Delta \sqrt{G_{\text {Ith }}}}{\sqrt{1-\sqrt{G_{\text {Imax }}} / \sqrt{G_{\text {Ic }}}}}\right)^{n}
$$

The equation for mode II growth is the same, but with the mode I values replaced by mode II values. Jones et al. further note that "the terms $\Delta \sqrt{G_{\text {Ith }}}$ and $\sqrt{G_{\text {Ic }}}$ are perhaps best viewed as parameters that are used to ensure that the entire range of data fits the equations [25]." This statement is somewhat puzzling. $\Delta \sqrt{G_{\text {Ith }}}$ and $\sqrt{G_{\text {Ic }}}$ are material parameters that can in principle be determined independently (especially $\sqrt{G_{\text {Ic }}}$ ). As such, their values should be fixed (given fixed material and environmental conditions, etc), and treating them as fitting parameters as suggested by Jones et al. is inappropriate. Equation 20 suggests a physical dependence between delamination growth, the growth threshold, and the critical SERR. If such a physical link exists and is correctly modelled it should not be necessary to modify the values of $\Delta \sqrt{G_{\text {Ith }}}$ and $\sqrt{G_{\text {Ic }}}$. Nevertheless, Jones et al. applied their equations to data found in literature and showed the $R$-ratio effect disappeared if the growth rate was plotted against $\Delta \sqrt{G_{\mathrm{I}}}-\Delta \sqrt{G_{\text {Ith }}} /\left(\sqrt{1-\sqrt{G_{\text {Imax }}} / \sqrt{G_{\text {Ic }}}}\right)$.

\subsection{Mode Mix}

The delamination growth behaviour of a material is known to depend upon the mix of opening modes. Research has focussed mainly on the effects of mode I and mode II, as for the loading conditions examined the mode III component is usually negligible. In cases where the mode III component is of sufficient severity however it is certainly capable of causing delamination growth [95]. A comprehensive overview of the various methods proposed to deal with mode mix has been provided by Blanco [96] and Blanco et al. [97].

The first to study mode-mix were Brussat and co-workers [40, 41], who suggested the purely empirical relationship:

$$
\Delta G_{\mathrm{eff}}=\left(1+\frac{2 G_{\mathrm{II}}}{G_{\mathrm{I}}+G_{\mathrm{II}}}\right) \Delta G_{\mathrm{I}}
$$

Of this equation Brussat et al. already noted "The equation is strictly empirical, and its form is subject to change in the future as a variety of mixed mode fatigue crack growth data becomes available [40]."

Mall et al. found that $G_{\mathrm{tot}}=G_{\mathrm{I}}+G_{\mathrm{II}}$ was best at correlating the delamination growth in the bonded FRP specimens they studied [31]. In a later paper [36] they argued that this was supported by the observations of crack displacements performed by Liechti and Knauss [98]. Xu et al. disputed these results [99]. They contended that $\Delta G_{\mathrm{I}}$ is the governing parameter for delamination growth, although the presented experimental evidence is not conclusive on this point: specimens tested under mode I and under mixed-mode did not show the same trend when the growth rate is plotted against $\Delta G_{\mathrm{I}}$.

A different approach was taken by Ramkumar and Whitcomb [100], who proposed the phenomenological formulation:

$$
\frac{d a}{d N}=C_{\mathrm{I}}\left(\frac{G_{\text {Imax }}}{G_{\text {Ic }}}\right)^{n_{\mathrm{I}}}+C_{\text {II }}\left(\frac{G_{\text {IImax }}}{G_{\text {IIc }}}\right)^{n_{\text {II }}}
$$


where $C_{\mathrm{I}}, n_{\mathrm{I}}, C_{\mathrm{II}}$, and $n_{\mathrm{II}}$ were determined experimentally, considering pure mode I, and pure mode II loading, respectively. Gustafson and Hojo [50] suggested a similar relationship, but using $\Delta G$ rather than $G_{\max }$.

Based on test results Russell and Street [101] developed the equation:

$$
\frac{d a}{d N}=C_{m}\left(\frac{\Delta G}{G_{\mathrm{c}}}\right)^{n_{m}}
$$

where $C_{m}$ and $n_{m}$ are determined from the values for pure mode I and pure mode II by means of a rule-ofmixtures, using $f_{\mathrm{I}}=G_{\mathrm{I}} /\left(G_{\mathrm{I}}+G_{\mathrm{II}}\right)$ and $f_{\mathrm{II}}=1-f_{\mathrm{I}}$ as weight factors.

Assuming linear damage accumulation in the process zone (i.e. validity of the Miner rule over small lengths), Andersons et al. [85] derived the relation:

$$
\frac{d a}{d N}=C\left[\left(\frac{K_{\mathrm{I}}}{K_{\mathrm{Ic}}}\right)^{2}+\left(\frac{K_{\mathrm{II}}}{K_{\mathrm{IIc}}}\right)^{2}\right]^{\frac{n}{2}}
$$

where $C$ and $n$ are both functions of the mode-mix angle, as well as the mode I and mode II fracture toughnesses $K_{\text {Ic }}$ and $K_{\text {IIc }}$. The mode-mix angle expresses the ratio between mode II and mode I loading, and is defined as:

$$
\psi=\tan ^{-1}\left(\frac{K_{\mathrm{II}}}{K_{\mathrm{I}}}\right)
$$

Kenanae and Benzeggagh [102] investigated unidirectional glass/epoxy composites and found a dependence between the Paris parameters $C$ and $n$, and the mode ratio $G_{\mathrm{II}} / G_{\text {tot }}$, where $G_{\text {tot }}=G_{\mathrm{I}}+G_{\mathrm{II}}$. Based on the observed dependence Kenane and Benzeggagh proposed the use of the Paris relation in terms of $\Delta G$, but with $C$ and $n$ defined as:

$$
\begin{aligned}
\ln (C) & =\ln \left(C_{\mathrm{II}}\right)+\left[\ln \left(C_{\mathrm{I}}\right)-\ln \left(C_{\mathrm{II}}\right)\right]\left(1-\frac{G_{\mathrm{II}}}{G_{\text {tot }}}\right)^{m_{C}} \\
n & =n_{\mathrm{I}}+\left(n_{\mathrm{II}}-n_{\mathrm{I}}\right)\left(\frac{G_{\mathrm{II}}}{G_{\text {tot }}}\right)^{m_{n}}
\end{aligned}
$$

where $m_{C}$ and $m_{n}$ are emprically determined parameters, considered by Kenane and Benzeggagh to be characteristic of the material under consideration.

Kardomateas et al. [103-105] considered the delamination growth to be a function of $G_{\max }$, the load ratio $G_{\min } / G_{\max }$, and the mode-mix angle, $\psi$, defined according to equation 25 . Based on these considerations they proposed the model:

$$
\frac{d a}{d N}=C(\psi) \frac{(\Delta \bar{G})^{m(\psi)}}{1-\bar{G}_{\max }}
$$

where $\bar{G}$ is a function of the SERR and the mode-dependent toughness $\Gamma_{0}$ :

$$
\bar{G}=\frac{G}{\Gamma_{0}(\psi)}
$$

$\Gamma_{0}$ is defined following Hutchinson and Suo [106]:

$$
\Gamma_{0}=G_{\text {Ic }}\left[1+(\lambda-1) \sin ^{2} \psi\right]^{-1}
$$

$\lambda$ is an experimentally determined parameter, equal to $G_{\text {Ic }} / G_{\text {IIc }}$. The advantage of this model is that it is a function of both $G_{\max }$ and $\Delta G$ and so fully captures the applied stress cycle. In light of the argument of Rans et al. [28], improvements in predictive performance may be expected if the similarity principle is correctly applied by using $\Delta \sqrt{G}$ in place of $\Delta G$. 
Blanco et al. [97] analysed experiment data from the literature [107] that showed that the mode-mix dependence was non-monotonic. To account for this Blanco et al. developed a model similar to that of Kenanane and Benzeggagh, but incorporating an extra quadratic term:

$$
\begin{gathered}
\log C=\log C_{\mathrm{I}}+\log C_{\mathrm{m}}\left(\frac{G_{\mathrm{II}}}{G_{\mathrm{tot}}}\right)+\log \frac{C_{\mathrm{II}}}{C_{\mathrm{I}} C_{\mathrm{m}}}\left(\frac{G_{\mathrm{II}}}{G_{\mathrm{tot}}}\right)^{2} \\
n=n_{\mathrm{I}}+n_{\mathrm{m}}\left(\frac{G_{\mathrm{II}}}{G_{\mathrm{tot}}}\right)+\left(n_{\mathrm{II}}-n_{\mathrm{I}}-n_{\mathrm{m}}\right)\left(\frac{G_{\mathrm{II}}}{G_{\mathrm{tot}}}\right)^{2}
\end{gathered}
$$

where $C_{\mathrm{m}}$ and $n_{\mathrm{m}}$ are empirically determined mixed-mode parameters. The calculated values of $C$ and $n$ are used in the Paris relation (equation 7 ), formulated with $f(G)=\Delta G / G_{\mathrm{c}}$.

Quaresimin and Ricotta $[108,109]$ proposed a Paris type growth relation as a function of $\Delta G_{\text {eq }}$, where $G_{\text {eq }}$ is defined as:

$$
G_{\mathrm{eq}}=G_{\mathrm{I}}+\frac{G_{\mathrm{II}}}{G_{\mathrm{I}}+G_{\mathrm{II}}} G_{\mathrm{II}}
$$

this is inserted into equation 7 to give:

$$
\frac{d a}{d N}=C\left(G_{\operatorname{Imax}}+\frac{G_{\mathrm{IImax}}}{G_{\operatorname{Imax}}+G_{\operatorname{IImax}}} G_{\mathrm{IImax}}-G_{\operatorname{Imin}}-\frac{G_{\mathrm{IImin}}}{G_{\operatorname{Imin}}+G_{\mathrm{IImin}}} G_{\mathrm{IImin}}\right)^{n}
$$

Quaresimin and Ricotta claim as a new feature of this formulation "the capability to explicitly account for the variation of the mode-mixity ratio with the crack length [109]." However if one considers that $G$ is in principle always a function of $a$, most of the models discussed above have this capability, although the mode-mix dependence is indeed not always as explicit as in the model proposed by Quaresimin and Ricotta.

It is notable that apart from the model of Kardomateas et al. all the proposed methods for predicting mixed-mode delamination growth express the delamination growth in terms of either $G_{\max }$ or $\Delta G$, and so rely on an incomplete description of the applied stress cycles. For all the methods using $\Delta G$ the argument of Rans et al. [28] applies: a correct application of the similarity principle requires the use of $\Delta \sqrt{G}$, and not $\Delta G$.

A number of papers have shown fractographic evidence for differences in the micro-mechanisms governing mode I and mode II delamination growth, e.g. [4, 67, 74, 86, 97, 110, 111]. Even so, nearly all the models discussed above are based on the observation of the macroscopic delamination growth behaviour, with no attempt to relate this to the micro-scale mechanisms which form the physical basis of the observed behaviour. An understanding of the micro-mechanics may point the way towards understanding the macroscopic behaviour. For example Singh and Greenhalgh [110] have suggested that the increased resistance to delamination growth under mode II loading is caused by the increased fracture surface area on the microscopic scale, when compared to mode I crack growth mechanisms. Chai has provided some more detailed considerations of this mechanism [112, 113]. O'Brien has also shown [111] this mechanism for mode II delamination, and on this basis argued that the commonly used $G_{\text {IIc }}$ is not a correct measure for the interlaminar shear toughness.

Singh and Geenhalgh suggest that mixed-mode delamination behaviour may be caused by the difference (increasing with an increasing proportion of mode II), between the preferred crack growth directions on the microscopic and macroscopic scale. Understanding and quantifying the interplay between the microscopic and macroscopic preferred growth directions may suggest an appropriate form for predicting mixed-mode delamination growth.

\subsection{Normalisation of the SERR}

A number of researchers have suggested that the SERR should not be entered directly into the Paris relation, but should be normalised by the critical SERR (fracture toughness), resulting in variations on the Paris relation such as:

$$
\frac{d a}{d N}=C\left(\frac{G_{\max }}{G_{\mathrm{c}}}\right)^{n} \quad \text { or } \quad \frac{d a}{d N}=C\left(\frac{\Delta G}{G_{\mathrm{c}}}\right)^{n}
$$


The first to suggest this approach were Wang et al., who claimed "...the quantity $G / G_{\mathrm{c}}$ represents the crack-driving force relative to the material's resistance [46]." Normalisation by the fracture toughness was adopted in a number of other investigations $[83,84,97,100,101,114]$. Note that since $G_{\mathrm{c}}$ is assumed to be constant (at least for a given mode mix and environmental conditions), it could in principle be included in the parameter $C$. The reason it is often included explicitly in the equation is the perceived relationship between the static fracture toughness and the resistance to fatigue delamination. The existence of such a relationship must be questioned however, as it has been shown that there is no direct correlation between resistance to static delamination growth (i.e. fracture toughness) and resistance to fatigue delamination growth [7, 67, 86, 99].

Poursartip proposed that the SERR should not be normalised by a static value, but instead by the parameter $G_{\mathrm{R}}(a)$, which represents the changing resistance to delamination growth over the course of a fatigue loading history [115]. This approach was also adopted by Shivakumar, Chen, and co-workers [116, 117] and Zhang, Peng, and co-workers $[118,119]$. The resistance to delamination growth is caused by a number of different mechanisms, such as: "matrix cracking and fiber bridging in the case of unidirectional composites; tow cracking, multiple delaminations, tow bridging, and tow breaking in the case of woven/braided fiber composites [116]." As such $G_{\mathrm{R}}$ is a phenomenological parameter that combines many different effects into one value, which is determined from the quasi-static delamination curve (R-curve). This raises the question whether the quasi-static and fatigue loading situations are in fact comparable. How much does a $G_{\mathrm{R}}$ value determined from a qausi-static delamination test really say about the fatigue behaviour?

In addition one can ask whether the delamination length $a$ is really a determining factor for mechanisms such as transverse cracking. A repeatable delamination growth rate (i.e. the same growth rate behaviour is seen if a test is done multiple times with identical conditions) means that $a$ is correlated to the number of applied cycles and therefore time. As a result the delamination length can act as a proxy for the number of applied cycles or the elapsed time. It is possible $G_{\mathrm{R}}$, or at least some of the mechanisms that determine $G_{\mathrm{R}}$, does not actually depend on the delamination length, but rather on some other quantity (such as number of cycles) for which the delamination length is merely acting as a proxy.

Zhang, Peng and co-workers addressed some of these issues by determining $G_{\mathrm{R}}$ in a different manner. At first they proposed determining $G_{\mathrm{R}}$ by a 're-loading' approach, where after a certain amount of fatigue loading the specimen is quasi-statically loaded until delamination growth is observed [118]. The SERR value at which delamination resumes under quasi-static loading is taken to be equal to $G_{\mathrm{R}}$. The disadvantage of this method is that the damage state of the fatigue specimen is destroyed, so further fatigue testing is no longer meaningful. Thus in a second paper [119] a new approach was proposed. In this method $G_{\mathrm{R}}$ is also determined from the R-curve. In contrast to the previous approaches however, $G_{\mathrm{R}}$ is not determined by taking the delamination length reached during the fatigue cycling. Instead an effective delamination length is used, such that the compliance of the static specimen(s) used to determine the R-curve is, at that effective length, equal to the compliance of the fatigue specimen. This has the advantage that damage states of the static and fatigue specimens may be more similar. The determined $G_{\mathrm{R}}(a)$ curve is still highly specific however, as it depends not only on the material used, but also on effects such as stacking sequence, due to the variety of mechanisms (potentially) involved. Furthermore an R-curve is constructed based on detected damage growth and thus is dependant on the experimental set-up. Thus an approach based on the cause(s) of the delamination resistance, rather than on the observed effect would be preferred.

Giannis et al. [120] and Murri [121, 122] have proposed normalisation by $G_{\mathrm{R}}$ as a method to account for fibre bridging during mode I fatigue testing. Fibre bridging is a consequence of using a unidirectional laminate in a test specimen, and will not occur if a laminate delaminates along an interface between two fibre layers with different orientations (a case which is more relevant to actual structures than the unidirectional laminate). Normalisation by $G_{\mathrm{R}}$ lowered the exponent in the Paris relation and also reduced the spread in the delamination growth data. Again however one must ask whether it is physically correct to relate delamination growth in fatigue to the R-curve in this way. Murri alreadly notes that the magnitude of fibre bridging during fatigue loading is probably lower than during quasi-static loading [122]. In addition the use of the the R-curve implies that the quasi-static delamination mechanism is the same as the fatigue delamination mechanism and that therefore the resistance to quasi-static growth also determines the resistance to fatigue growth. Recent fractographic evidence [123] suggests that this is in fact not the case. 


\subsection{Effect of environmental and testing conditions}

The effect of temperature on delamination growth rate in composite laminates has been investigated by Chan and Wang [83], Sjögren and Asp [124], Shindo et al. [125-127], and Coronado et al. [128]. Burianek and Spearing [129] and Rans et al. [130] studied the effect of temperature on delamination of FMLs. Ashcroft, Shaw and co-workers $[131,132]$ investigated adhesively bonded composites.

All these researchers have reported that the temperature during the test affected the delamination growth rate. Generally, a higher temperature means a higher growth rate. Some exceptions have been noted however: Chan and Wang [83] reported that specimens tested at low temperature $\left(-55^{\circ} \mathrm{C}\right)$ had the lowest fracture toughness (though the effect on growth rate is less clear). Ashcroft and Shaw. [132] also found higher growth at low temperature, suggesting that the effect of temperature may be strongly dependant on the matrix or adhesive material.

Rans et al. [130] reported non-monotonous behaviour. In their experiments the delamination growth rate at low temperature $\left(-40^{\circ} \mathrm{C}\right)$ was lower than that at elevated temperature $\left(70{ }^{\circ} \mathrm{C}\right)$, but higher than the room temperature rate. Rans et al. do not offer an explanation for this behaviour. Shindo et al. [125-127] also found non-monotonous behaviour. They reported that the delamination growth rate at $4 \mathrm{~K}$ was lower than that at room temperature, but higher than at $77 \mathrm{~K}$. They suggest this can be explained by a better fibre-matrix adhesion at lower temperatures, which is supported by fractographic evidence [125].The lowered resistance to delamination growth at $4 \mathrm{~K}$ is explained by the freezing of the molecular motion of the epoxy resin, which prevents stress relaxation. In addition Shindo et al. refer to the work of Hartwig and Knaak [133], showing that $4 \mathrm{~K}$ thermal residual stresses will arise at the fibre-matrix interface and that the matrix will be embrittled. Shindo et al. suggest these effects contribute to the lower resistance to delamination growth at $4 \mathrm{~K}$, when compared to $77 \mathrm{~K}$.

Of the researchers discussed above, only Burianek and Spearing [129] attempted to find a quantitative relationship between temperature and growth rate. They included an Arrhenius relationship in the Paris relation, based on the use of the Arrhenius equation to describe the temperature dependence of creep behaviour in metals. The proposed relationship has the form:

$$
\frac{d a}{d N}=C e^{\left(\frac{-Q}{R T}\right)}(\Delta G)^{n}
$$

where $R$ is the universal gas constant, $Q$ is the activation energy, $T$ is the temperature, and $C$ and $n$ are the Paris parameters. Although this equation successfully correlated the results, it is not immediately obvious why an equation used for creep in metals should work for delamination growth in composites. Another aspect that remains unclear is that the value of the activation energy was calculated as ranging from 12 to $17 \mathrm{~kJ} / \mathrm{mol}$. How Burianek and Spearing calculated these values is not reported however.

The effect of moisture on delamination growth was investigated by Chan and Wang [83] and Russell and Street [134]. Both found that moisture decreased the fracture toughness, although the effect on delamination growth was less clear. Hojo et al. [135] also investigated the effect of moisture in composite laminates, looking at two different resin types. They found that moisture generally increased the delamination growth rate and reduced the delamination threshold. The magnitude of the effect depended on the material investigated. Based on fractography Hojo et al. suggest that the change in growth rate can be explained by a change of mechanism from matrix cracking to fibre-interface disbonding.

Acceleration of the delamination growth due to moisture content was also reported by Fernando et al. [136] and Jethwa and Kinloch [137]. No quantitative dependence has so far been proposed however. The specimens of Jethwa and Kinloch were examined using elemental mapping X-ray photoelectron spectroscopy and a number of other techniques, which was reported in a second paper [138]. This analysis suggested that moisture changed the locus of failure of the adhesive bond, thus causing a different failure mechanism (with a different SERR vs growth rate relationship) to be dominant. More recenctly Landry et al. [139] also found that exposing carbon/epoxy composites to water, hydraulic fluid, or de-icing fluid prior to fatigue loading increases the delamination growth rate. 


\subsection{Full SERR range models}

The Paris relation as given by equation 7 describes a straight line when plotted on a log-log scale. This relation generally holds over a certain range of values of $G_{\max }$ or $\Delta \sqrt{G}$. However already during the early investigations of Mostovoy and Ripling [7] it was known that the full fatigue behaviour has a sigmoidal shape, as shown in figure 1. The Paris relation describes region II of this behaviour, but fails to capture the threshold and unstable growth regions (region I and III). To create a delamination growth model that is valid over the full SERR range, Martin and Murri [79] proposed the power law expression:

$$
\frac{d a}{d N}=C\left(G_{\max }\right)^{n} \frac{\left[1-\left(\frac{G_{\text {th }}}{G_{\max }}\right)^{n_{1}}\right]}{\left[1-\left(\frac{G_{\max }}{G_{c}}\right)^{n_{2}}\right]}
$$

Note that this expression was based on the observed shape of the $d a / d N$ vs $G$ graph, and not on physical considerations. Based on the same line of reasoning as that of Martin and Murri, equation 37 was also proposed by Kinloch and Osiyemi [140], who used it to predict the life of adhesively bonded single lap joints. This approach was further explored in a number of later papers [141-143]. Abdel Wahab et al. [144] also used a relation similar to equation 37 to find the fatigue life of adhesive bonds, but included a mode-mix dependence.

Shivakumar, Chen, and co-workers $[116,117]$ have proposed a number of variations of equation 37, making use of the length dependent delamination resistance $G_{\mathrm{IR}}$ as proposed by Poursartip [115]. This model was applied to a T700 carbon / vinyl ester composite [145]. Reasonably good agreement was found for the loglinear growth region, though with a scatter band spanning roughly an order of magnitude. Unfortunately little to no experimental data was presented for the threshold and unstable growth regions, making it hard to evaluate the correctness of the model. Giannis et al. [120] also present a model of the form of equation 37 , but again the experimental data does not clearly show a threshold or unstable growth region, making it difficult to evaluate the performance of the model outside the log-linear region.

To generate a full SERR range model, the value of the fatigue delamination threshold $G_{\mathrm{th}}$, i.e. the SERR value below which no delamination growth occurs, is required. If a specimen is used in which the SERR reduces with increasing delamination length (e.g. a double cantilever beam (DCB) specimen), the threshold can be determined by continuing the fatigue test until no further growth is observed after a set number of cycles. However, if fibre bridging occurs in the specimen (e.g. for a unidirectional laminate) the resulting threshold value will be artificially high [120]. Instead it may be better to determine the fatigue threshold by performing a delamination onset test, to minimise the effect of fibre bridging. A standard test method for delamination onset has been proposed by the American Society for Testing and Materials [146]. In this method several specimens are cyclicly loaded with different $G_{\max }$ values below $G_{\text {Ic }}$ until delamination onset occurs. The number of cycles at which onset occurs is recorded and in this way a G-N curve (analogous to the S-N curve) for delamination onset can be constructed. If this curve shows a 'fatigue limit' (i.e. a SERR value below which no onset occurs) this is taken to be the threshold level.

Although a model based purely on the log-linear region II may be sufficient for many delamination growth analyses, a true understanding of the physics of the delamination problem should allow the formulation of a model that covers the entire range of delamination behaviour from the growth threshold through to unstable delamination growth. Such a model would link successful log-linear growth models to models for static delamination growth.

\subsection{Variable Amplitude Fatigue}

Delamination growth due to variable amplitude (VA) fatigue has so far not received much attention. Investigations have been reported by Schön and Blom [147] and Bathias and Laksimi [49] who studied FRPs, and by Marissen [73, 148] and Khan et al. [149] who examined VA delamination growth in FMLs. An investigation by Martin on variable amplitude fatigue in FRPs has been included in the Composite Materials Handbook [150]. This investigation indicated that history effects were relatively small, but suggested that further work is necessary to check the robustness of the results to variations in material and lay-up. Schön 
and Blom modelled the delamination growth by assuming linear damage accumulation (so basically a variant of the Miner rule). As delamination growth interacts with other damage modes, such as transverse cracking $[64,65]$, it seems somewhat unlikely that linear damage accumulation would hold for all materials and load cases, since that would imply the absence of any history or interaction effects. Indeed, Marissen reported that load history had an effect on the delamination growth and thus that linear damage accumulation is insufficient to predict the delamination growth rate [73, 148]. In contrast Khan et al. [149] reported an absence of interaction effects for delamination growth in Glare (a glass fibre / aluminium FML). Khan et al attribute these differences to the differences in the specimen configuration: Marissen used ARALL (aramid/aluminium) with woven fibre layers, whereas Khan et al. used Glare, with unidirectional fibre layers. Bathias and Laksimi [49] also reported there were no history effects for delamination in glass/epoxy composites.

For an understanding of the fatigue behaviour of structures in actual service a better understanding of the effect of VA fatigue is crucial. More research is therefore needed on this topic.

\subsection{Other Approaches}

A number of researchers have suggested fracture mechanics based approaches that do not fit into the categories described above. Those will be discussed in this section.

Schön noted that as the Paris relation forms a straight line (in a log-log plot) it can be defined by two points [151]. Schön proposed the use of the threshold growth value and the onset of unstable delamination growth. According to Schön the threshold SERR value is independent of mode-mix and $R$. Note this is not in agreement with other results published in literature [2, 29, 85, 152]. Schön further contends that the critical delamination growth rate (but not the attendant SERR value) is independent of mode-mix and $R$, which would seem to be merely a question of definition. Using the threshold and critical values Schön then derived the Paris parameters as:

$$
\begin{aligned}
& C=\frac{\left(\frac{d a}{d N}\right)_{\mathrm{th}}}{\Delta G_{\mathrm{th}}} \\
& n=\frac{\log \left(\frac{d a}{d N}\right)_{\mathrm{th}}-\log \left(\frac{d a}{d N}\right)_{\mathrm{c}}}{\log \left[\Delta G_{\mathrm{th}}\right]-\log \left[G_{\max , \mathrm{c}}-\left(1-Q^{2}\right)\right]}
\end{aligned}
$$

Here $Q$ is a restatement of the $R$-ratio as:

$$
\begin{array}{ll}
Q=R & \text { when }-1 \leq R \leq 1 \\
Q=\frac{1}{R} & \text { when } \quad|R|>1
\end{array}
$$

Schön adopted the $Q$-ratio as he contends there is no difference between compression-compression and tension-tension loading. Considering the possible occurrence of buckling in compression-compression loading, this claim is questionable. In a later paper [153] Schön investigated tension-compression loading, which based on reference [154] he claims is the most severe loading condition. Using the model described in reference [151] he derived that the most severe loading ratio is $R=-1$. It is not clear exactly what specimen and loading configuration Schön is considering, but a consideration of the physics shows that his conclusion can not hold for pure mode I loading at least, since in pure mode I the delamination will be closed during the compression part of the loading cycle.

In essence the approach described by Schön is a strategy for experimentally determining the Paris curve. Schön claims that this proposed approach will greatly reduce the amount of work needed to characterize the fatigue delamination growth [151]. The correctness of this assertion is doubtful. Typically, finding the fatigue threshold requires a large number of long duration tests. It is not evident that this would require less effort than generating data points along the log-linear range of $d a / d N$ vs SERR values and then finding $C$ and $n$ by curve fitting. Furthermore, Schön's model does not account for the effect of the $R$-ratio (possibly due to using $\Delta G$ rather than $\Delta \sqrt{G}$ ) or mode-mix, making the value of this approach limited. 
A novel approach was taken by Dahlen and Springer [155], who used a dimensional analysis based on the Buckingham $\Pi$ theorem [156]. For the growth during one cycle they derived the relationship:

$$
\Delta a \frac{\sigma_{\mathrm{f}}^{2}}{E_{\mathrm{y}} G_{\mathrm{c}}}=C\left(U \frac{G_{\max }}{G_{\mathrm{c}}}\right)^{n}
$$

where $\sigma_{\mathrm{f}}$ is the ply strength, $E_{\mathrm{y}}$ is the transverse ply modulus and $U$ is a function of $G_{\max } / G_{\mathrm{c}}$ and $G_{\min } / G_{\max }$. By analogy to the situation in metals $G_{\mathrm{c}}, \sigma_{\mathrm{f}}$ and $E_{\mathrm{y}}$ were selected as controling variables. The form of $U$ depends on the presence of shear reversal. If shear reversal occurs then:

$$
U=\left[\frac{G_{\min }}{G_{\max }}+\frac{G_{\max }}{G_{\mathrm{c}}}\left(1-\frac{G_{\min }}{G_{\max }}\right)\right]^{u}
$$

In the absence of shear reversal $U$ is given by:

$$
U=\left(1-\frac{G_{\min }}{G_{\max }}\right)\left[1+\frac{G_{\min }}{G_{\max }}\left(\frac{G_{\max }}{G_{\mathrm{c}}}-1\right)\right]^{u}
$$

The parameters $C, n$, and $E_{\mathrm{y}} G_{\mathrm{c}} / \sigma_{\mathrm{f}}^{2}$ are functions of the mode mix and the pure mode I and mode II values of these parameters, similar to the Russell-Street model [101], though with different 'mixing functions' and weight factors.

Note that the parameter $\sigma_{\mathrm{f}}^{2} / E_{\mathrm{y}} G_{\mathrm{c}}$ is a constant (assuming the temperature does not change significantly) and that $U$ is an effective stress ratio, like the one originally proposed by Elber for mode I crack growth in aluminium [80]. In other words, the model proposed by Dahlen and Springer can be reduced to a Paris type relation of the form:

$$
\frac{d a}{d N}=C f\left(G_{\max }, R\right)^{n}
$$

At first glance the model proposed by Dahlen and Springer as given by equation 42 looks promising, as it appears to take account of the physics of the problem. However the failure to replace the parameters $C$ and $n$ by independently determinable material properties implies that not all the quantities controlling the delamination behaviour were identified. Given that $C$ must be determined by curve fitting of delamination growth results, any constant value can be 'extracted' from $C$ without affecting the correlation of the resulting power-law relation. Thus if a quantity is extracted from $C$, a rigorous physical justification should be given for the importance of that quantity, or there is no added value in including it separately in the equation. Such a justification is lacking for the quantity $E_{\mathrm{y}} G_{\mathrm{c}} / \sigma_{\mathrm{f}}^{2}$ proposed by Dahlen and Springer.

Wimmer and Pettermann employed the growth relation proposed by Dahlen and Springer in a semianalytical model of delamination growth [157]. Unfortunately they do not provide an experimental validation of their model. Wimmer et al. [158] did compare the predictions for quasi-static loading generated by the model proposed in reference [157] with experimental values. The correspondence between the predicted and experimental behaviour was not very good however.

Xie and Biggers have proposed a fracture mechanics approach based on the use of the FEM [159, 160]. In this approach the interface along which the delamination growth occurs is modelled by plate elements connected by springs. Three springs are used per connected node in order to model each of the opening modes. Delamination growth is simulated by deleting the springs (or reducing their stiffness to 0 ) when a fracture criterion is exceeded. Xie and Biggers used a criterion of the form:

$$
\left(\frac{G_{\mathrm{I}}}{G_{\mathrm{Ic}}}\right)^{\alpha}+\left(\frac{G_{\mathrm{II}}}{G_{\mathrm{IIc}}}\right)^{\beta}+\left(\frac{G_{\mathrm{III}}}{G_{\mathrm{IIIc}}}\right)^{\gamma}=1
$$

Xie and Biggers also used an ingenious technique employing two vectors to describe the delamination front at the connecting nodes in order to avoid the need to perform re-meshing after each delamination growth step. Although they do not state it explicitly, Xie and Biggers only employed their model in the investigation of delamination growth under quasi-static load. However Boscolo, Zhang, and co-workers [161-165] have 
used a similar approach to model delamination growth in a strap bonded to a plate in which a fatigue crack is growing. There is a serious problem with applying this apporach to fatigue delamination growth however, which can be seen by conducting a simple thought experiment.

Imagine a configuration containing a delamination. The first fatigue cycle is simulated by applying the maximum fatigue load to the configuration. The SERR is computed at each node along the delamination front. If the fracture criterion is exceeded the node is released. The SERR is the computed again for the new delamination front, and again nodes are released if the fracture criterion is exceeded. This process continues until the fracture criterion is no longer exceeded. The delamination front will now be in equilibrium and no further delamination growth will be predicted by the model, no matter how many extra fatigue cycles are numerically applied. In other words, the fracture criterion approach can only predict delamination growth due to quasi-static load, and not fatigue delamination growth.

Despite this, Boscolo, Zhang and co-workers [161, 163, 165] present test results which are in reasonably good agreement with the growth predicted using the fracture criterion method. The reason for this is that Boscolo et al. model a strap bonded to a metal plate containing a fatigue crack. The growth of this crack in successive fatigue cycles perturbs the equilibrium of the delamination front, allowing growth to occur. Boscolo and Zhang justify their approach with the statement: "It must be said, though, that disbond growth in patch repair and bonded crack retarders is mostly due to the high local stresses in the substrate crack tip region due to the "stress singularity" effect rather than fatigue loads [164]." However in the experimental results presented in reference [165, fig. $6 \mathrm{~b}$ ] there is a quite clearly visible delamination that did not form in the substrate crack tip region. As the adopted method already requires the computation of the SERR, a more appropriate SERR based growth law could be applied to predict the delamination growth.

\subsection{Concluding remarks on the fracture mechanics based methods}

Starting with the efforts of Roderick et al. [6], and Mostovoy and Ripling [7], the fracture mechanics based methods have undoubtedly been successful at describing fatigue delamination growth behaviour. However this success can be largely ascribed to the presence of "constants" that are to be empirically derived in these methods. These curve fitting parameters give researchers the freedom to make a wide variety of suggested models fit the experimental data. As a result, a wide range of models have been proposed to deal with a variety of factors such as the $R$-ratio effect, mode-mix and environmental influences. Only rarely are these models based on a consideration of the physics of the problem however. During the earliest developments the Paris relation was adopted, not based on a consideration of the mechanisms at work in delamination in composites or adhesive bonding, but based on its success at predicting fatigue crack growth in metals. Since those investigations the Paris relation has usually been taken as a given, or as a starting point for modification to include some extra effect such as mode-mix. These modifications are usually only based on a phenomenological description of the macroscopic delamination growth behaviour, and not on an understanding of the physics underlying the problem. This lack of connection to the underlying physics can lead to issues such as the observation of an $R$-ratio effect when an incomplete description of the stress cycle is used as a similarity parameter. Another issue is that the limits of the applicability of developed models are unclear, with not only material but even geometry possibly effecting the models. Fracture mechanics based models have shown great potential to predict delamination growth, but they need to be tied into the physics to allow true understanding of the material behaviour.

\section{Cohesive Zone Models}

Like the VCCT, the CZM approach is a finite element method. When employing the VCCT in a predictive model, remeshing is required as the crack advances. In the CZM approach this is avoided, by modelling the interfaces along which delaminations are expected to grow using cohesive zone elements. These elements are not linear elastic, but follow a prescribed traction-displacement relation. Often some kind of damage parameter is used to progressively reduce the stiffness, simulating damage growth within the element. Thus 
the constitutive behaviour of the cohesive element is generally defined as (a variation of):

$$
\begin{array}{rll}
T_{i}=K_{i} \delta_{i} & \text { if } & 0 \leq \kappa_{i} \leq \delta_{i}^{0} \\
T_{i}=\left(1-D_{i}\right) K_{i} \delta_{i} & \text { if } & \delta_{i}^{0} \leq \kappa_{i} \leq \delta_{i}^{f} \\
T_{i}=0 & \text { if } & \delta_{i}^{f} \leq \kappa_{i}
\end{array}
$$

where $\kappa(t)_{i}=\max _{0 \leq \tau \leq t} \delta_{i}(\tau) ; \delta_{i}(t)$ is the current value of the relative displacement of the faces of the cohesive element at (pseudo-) time $t, D_{i}$ is the damage parameter, the index $i$ represents the direction, $\delta^{0}$ is the displacement at the onset of softening of the element, $\delta^{f}$ is the displacement at failure, $K_{i}$ is the stiffness and $T_{i}$ is the traction.

CZMs have enjoyed some success in the prediction of both static and fatigue delamiation growth. An overview of the development of the CZM will be given in this section.

\subsection{Early CZM approaches}

The basis for CZMs were the cohesive zone formulations developed by Dugdale [166] and Barenblatt [167]. Based on their concepts Needleman [8, 168], studied a number of fundamental decohesion problems using a CZM. Other applications followed in the decade after. Hutchinson and Evans have written a concise overview of these investigations [169]. Camanho et al. have also provided a review of the early developments of CZMs [170]. To model fatigue delamination growth an irreversible stiffness reduction must be added to the CZM formulation [171]. Needleman was also the first to propose such a formulation [172], followed by Camacho and Ortiz [173]. These ideas were further developed into models for fatigue growth by Foulk et al. [174], de-Andrés et al. [175], Nguyen et al. [176], Yang et al. [177] and Roe and Siegmund [171].

Foulk et al. [174] included unloading and reloading behaviour in their constitutive model. This resulted in an irreversible behaviour of the traction-separation relation. Andrés et al. [175] took a similar approach, but also proposed a damage parameter defined as:

$$
D=\frac{\phi\left(\delta_{\max }\right)}{G_{\mathrm{c}}}
$$

where $\phi$ is the potential associated with the traction-displacement relation and $\delta_{\max }$ is the maximum displacement reached during the loading portion of a load cycle. The value of the damage parameter is extrapolated by means of a one-term Taylor series expansion and is used to 'fast-forward' the loading-unloading behaviour of the traction-separation law. This allows the damage length to be evaluated at a limited set of cycle numbers, without the need to find the intermediate behaviour by means of a cycle-by-cycle analysis.

Nguyen et al. used an exponential decay factor to reduce the stiffness and traction as a function of the number of cycles [176]. Yang et al. [177] formulated a damage parameter such that damage was also accrued during the unloading portion of the load cycle. This formulation allows both initiation and growth to be modelled with the same law, but does require separate crack advance criteria. Roe and Siegmund [171] proposed a damage parameter that is applied to the traction-separation behaviour and thereby also governs the unloading and reloading behaviour. Separate crack advance criteria are not necessary for that formulation. Camanho et al. [178] introduced a damage parameter that is dependant on the mode-mix:

$$
D=\frac{\delta_{m}^{f}\left(\kappa_{m}-\delta_{m}^{0}\right)}{\kappa_{m}\left(\delta_{m}^{f}-\delta_{m}^{0}\right)}
$$

Here $D$ is the damage parameter, which is used to reduce the stiffness of the cohesive element. $\delta_{m}$ is the mixed mode relative displacement of the cohesive zone faces, defined as:

$$
\delta_{m}=\sqrt{\delta_{1}^{2}+\delta_{2}^{2}+\left\langle\delta_{3}^{2}\right\rangle}=\sqrt{\delta_{\text {shear }}^{2}+\left\langle\delta_{3}^{2}\right\rangle}
$$

where $\delta_{i}$ inidcates the displacement in the i-direction, with the 3 -direction being out of plane, and $\langle x\rangle$ is the Macauley operator (i.e. zero if $x$ is smaller than zero and equal to $x$ otherwise). $\kappa_{m}$ again indicates the 
maximum displacement reached. Based on a facture criterion proposed by Benzeggagh and Kenane [179], Camanho et al. take the following equations for the displacement at failure:

$$
\delta_{m}^{f}=\left\{\begin{array}{l}
\frac{2}{K \delta_{m}^{0}}\left[G_{\mathrm{Ic}}+\left(G_{\mathrm{IIc}}-G_{\mathrm{Ic}}\right)\left(\frac{\beta^{2}}{1+\beta^{2}}\right)^{\eta}\right], \delta_{3}>0 \\
\sqrt{\left(\delta_{1}^{f}\right)^{2}+\left(\delta_{2}^{f}\right)^{2}}, \delta_{3} \leq 0
\end{array}\right.
$$

where $\beta$ is the mixed-mode ratio $\delta_{\text {shear }} / \delta_{3}$ and $\eta$ is an empirically determined parameter. Note that the Benzeggagh-Kenane criterion is empirical, based on a curve fit of the macroscopically observed behaviour of a static delamination test.

\subsection{Further developments}

Robinson et al. [180] proposed a damage parameter that was split into two parts: one for the static portion of delamination growth and one for the fatigue portion. The evolution of this damage parameter followed the relation proposed by Peerlings et al. [181] and the interface elements and cohesive laws were based on the work of Alfano and Crisfield [182]. Robinson et al. simulated the fatigue behaviour by numerically applying a constant load equal to the maximum of the fatigue load, and treating the damage parameter and displacement as dependant on pseudo-time, as represented by the number of cycles. The damage parameter derived by Robinson et al. is:

$$
D(N+\Delta N)-D(N)=\frac{\delta^{0} \delta^{f}}{\delta^{f}-\delta^{0}}\left(\frac{1}{\kappa(N)}-\frac{1}{\kappa(N+\Delta N)}\right)+\Delta N \frac{C}{1+\beta} e^{\lambda D_{\mu}}\left(\frac{\delta_{\mu}}{\delta^{f}}\right)^{1+\beta}
$$

where $C, \beta$, and $\lambda$ are fitting parameters. The first term of the right hand side of this equation describes the quasi-static portion of the delamination and the second term describes the fatigue portion of the delamination. $x_{\mu}$ denotes the following operation:

$$
x_{\mu}=(1-\mu) x(N)+\mu x(N+\Delta N)
$$

Robinson et al. use this operation to evaluate the integral of the fatigue damage parameter rate:

$$
\int_{N}^{N+\Delta N} C e^{\lambda D}\left(\frac{\delta}{\delta^{f}}\right)^{\beta} d N
$$

Robinson et al state: "In all computations shown in this paper the value $\mu=0.7$ has been used giving satisfactory results, but the problem of finding an optimal value of $\mu$ is not trivial [180]." This statement is rather peculiar. Equation 53 defines a mathematical operation, not a physical model. That using a certain value of $\mu$ gives satisfactory results in no way implies that those results are also correct. Furthermore, using the same value of $\mu$ for all integration intervals is only correct if the function being integrated has a constant slope, which for $\delta(N)$ at least is not true, as can be seen in the Robinson et al. paper [180, fig.6].

Muñoz et al. [183] investigated the sensitivity of the model of Robinson et al. to the pseudo-time increment $\Delta N$, and to the mesh size. To improve the performance of the model they suggested using the "elastic limit" of the relative displacement (the displacement for maximum traction) rather than the failure limit of the relative displacement as the reference length in the damage parameter.

In the model proposed by Robinson et al. a new set of parameters has to be determined for each modemix ratio. Tumino and Cappello [184] modified this model by relating the model parameters $C$ and $\beta$ with the mode-mix in a manner similar to the way Blanco et al. [97] related the Paris parameters $C$ and $n$ to the mode-mix. Robinson et al. [180], Muñoz et al. [183], and Tumino and Cappello [184] all present comparisons between predictions produced with (derivatives of) the model proposed in reference [180] and experimental data. In each case the same dataset is used [107] and good agreement is shown. However this dataset was also used to find the required input parameters of the model. Thus the demonstrated agreement between the model and the experimental data is tautological. Until the model is compared to a new dataset it can not be considered to be validated. 
A different split parameter was proposed by Harper and Hallet [185]. In this model the static component of the damage parameter is defined as:

$$
D_{s}(\delta)=\frac{\delta-\delta^{0}}{\delta^{f}-\delta^{0}}
$$

For the fatigue component, the model of Blanco et al. [97] (see equations 31 and 32) is used to predict the delamination growth rate. From this growth rate the matching fatigue damage zone size and fatigue damage growth rate are calculated. The fatigue component of the damage parameter follows from the fatigue damage growth rate. Such a linkage between CZM and fracture mechanics was originally proposed by Turon et al. [186]. The SERR required as input for the Blanco model is calculated by integrating the traction-displacement curve of the cohesive element. Essentially, the model proposed by Harper and Hallet provides a more complex method of calculating the SERR, but is otherwise not much different from the model proposed by Blanco et al. Harper and Hallet present a comparison between their model and experimental data reported by Asp et al. [107]. However this data was also used to find the empirical parameters in the Blanco model (and thus in the Harper-Hallet model). Therefore this comparison can not be regarded as a validation of the Harper-Hallet model, and one must conclude a comparison with new experimental data remains necessary.

Moroni and Pirondi $[187,188]$ similarly proposed a CZM linked to fracture mechanics. In their model the change of the damage parameter is defined as:

$$
\frac{d D}{d N}=\frac{1}{A_{\mathrm{CZ}}} f(\Delta G)
$$

where $A_{\mathrm{CZ}}$ is the area spanned by a cohesive element. For $f(\Delta G)$ Moroni and Pirondi compared three mixed mode models, viz: the model proposed by Kenane and Benzegaggh [102], the model proposed by Quaresimin and Ricotta [109], and what Moroni and Pirondi describe as "the simplified version of a model proposed by Abdel Wahab et al. [ref: [144]]". In fact this third model goes back to the work of Ramkumar and Whitcomb [100] and Gustafson and Hojo [50]. Abdel Wahab et al. [144] also proposed a model of this form, but using a sigmoidal formulation rather than simply $G_{\max }$ [100] or $\Delta G$ [50]. In reference [188] Moroni and Priondi compare the results of their model with "analytical" results produced by using the normal, non-CZM, formulation of the models used in their CZM. Although Moroni and Prondi refer to these results as "analytical" the SERR was calculated by means of VCCT, which is a finite element technique. Unsurprisingly the agreement between the CZM and the "analytical" results was good, because the model proposed by Moroni and Priondi is effectively a numerical integration scheme. The only difference is the calculation of the SERR, which will be slightly different due to the softening of the cohesive elements in the vicinity of the crack tip.

Recently Landry and LaPlante have also proposed a model linking fracture mechanics and CZM [189], with the damage parameter depending on a modified Paris relation applied to $G_{\text {Imax }}$. They used this model to predict delamination growth as a result of variable amplitude loading. The predictions were compared with fatigue tests of two specimens and good agreement was found. Only 12,000 cycles were applied, which is a rather short period. It would be interesting to investigate the Landry-LaPlante model for a longer duration test.

Khoramishad et al. [190] proposed a damage parameter based on the maximum strain, according to:

$$
\begin{aligned}
& \frac{\Delta D}{\Delta N}=\left\{\begin{array}{rr}
C\left(\epsilon_{\max }-\epsilon_{\mathrm{th}}\right)^{n} & \epsilon_{\max }>\epsilon_{\mathrm{th}} \\
0 & \epsilon_{\max } \leq \epsilon_{\mathrm{th}}
\end{array}\right. \\
& \epsilon_{\max }=\frac{\epsilon_{n}}{2}+\sqrt{\left(\frac{\epsilon_{n}}{2}\right)^{2}+\left(\frac{\epsilon_{s}}{2}\right)^{2}}
\end{aligned}
$$

where $\epsilon_{\max }$ is the maximum principal strain in the cohesive element, $\epsilon_{\mathrm{th}}$ is the threshold strain, below which no fatigue damage occurs, $\epsilon_{n}$ is the normal component of the strain, and $\epsilon_{s}$ is the shear component of the strain. The traction-displacement behaviour was defined such that softening starts at a displacement value 
$\delta_{i}^{0}$ where the matching peel or shear traction exceed the critical peel or shear values, i.e:

$$
\max \left[\frac{\left\langle t_{I}\right\rangle}{T_{I}}, \frac{t_{I I}}{T_{I I}}\right] \geq 1
$$

Failure displacement $\delta_{i}^{f}$ was defined using the Benzeggagh-Kenane fracture criterion [179] also used by Camanho et al [178]. The cohesive behaviour was determined by correlation with static tests. The damage parameter was calibrated using a fatigue test on one joint configuration. The model was then validated by experiments on a second configuration. Khoramishad et al. produced a load-life diagram and predicted the back-face strain at the point where a strain gauge was applied during the experiments. The experimental and numerical results showed good agreement. An $a$ vs $N$ or $d a / d N$ vs $G$ diagram would have been useful to evaluate the propagation predictions of the model, but these were unfortunately not supplied.

May and Hallet developed a CZM that not only includes delamination propagation, but also predicts initiation [191, 192]. To predict initiation the load severity (the ratio of applied load to static failure load) is calculated for elements along the interface. The severity is compared to reference $\mathrm{S}-\mathrm{N}$ data and then used to update a damage parameter $d_{f, i}$ accordingly. When $d_{f, i}$ for an element reaches 1 , the element properties are reduced to 0 over a number of subsquent cycles. Element degradation due to fatigue damage is only applied when $d_{f i, i}$ is equal to 1 , to prevent redistribution of load to other elements, which May and Hallet claim does not occur during the initiation process. The numerical damage initiation is not just applied to one element, but to all elements in an initiation zone in the vicinity of the element with the highest failure index, which is the ratio of the mixed-mode SERR of an element to the critical mixed-mode SERR. After a crack is initiated, propagation is predicted using a damage parameter which is incremented based on the Paris relation (equation 7).

\subsection{Concluding remarks on the CZM}

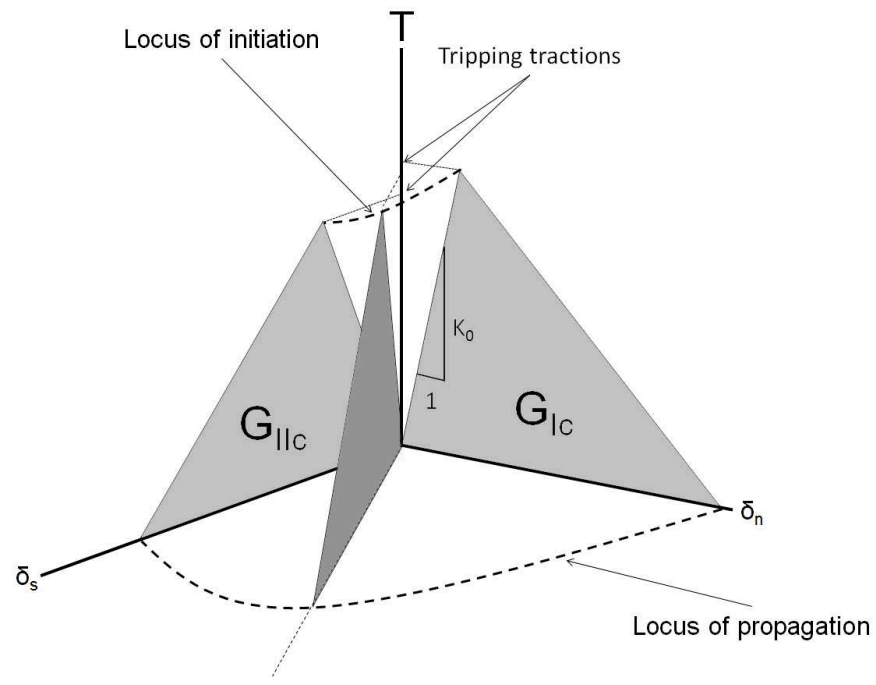

Figure 2: A typical cohesive model. $T$ is the traction, $\delta_{n}$ is the normal (mode I) displacement, and $\delta_{s}$ is the shear (mode II and III) displacement. The indicated quantities (initial stiffness $K_{0}$, critical SERRs $G_{\text {Ic }}$ and $G_{\text {IIc }}$, and the loci of initiation and propagation) must be assumed or determined experimentally.

The CZM approach suffers from the same shortcomings as the fracture mechanics based methods, i.e. a lack of grounding in an understanding of the physics underlying the delamination process. This is seen both in the cohesive relation itself and in the damage parameter formulations. Consider for example a typical mixed-mode cohesive relation as shown in figure 2. The initial stiffness $K_{0}$ is chosen for purely numerical reasons [190]. The loci of initiation and propagation are usually determined by means of a 
(phenomenological) criterion based on the pure mode I and mode II values. The criterion for the locus of initiation makes use of the tripping tractions, which are difficult to determine experimentally. For that reason the tripping traction is often treated as a penalty parameter, i.e. an assumed value is used [190].

The locus of propagation is based on the area under the traction-separation curve, which is assumed to be equal to $G_{\mathrm{c}}$. Note that this implies that the work applied to the cohesive element is solely dissipated by the formation of the new fracture surface, even though the softening of the cohesive element would suggest a measure of plastic deformation.

Summarising, to correctly define the cohesive zone a number of parameters need to be determined. Of these parameters only the values of $G_{i c}$ are determined experimentally, the others are chosen based on numerical considerations. Even the $G_{\mathrm{c}}$ values may be treated as fitting parameters however; consider for example the following statement of Khoramishad et al: "The initial value of $G_{\mathrm{c}}$ used was typical of the range of values found in the literature for the FM $73 \mathrm{M}$ adhesive. This was refined along with the tripping traction in an informed iterative technique to match the static responses of the bonded joints [190]." If $G_{\mathrm{C}}$ has physical significance it should not be necessary to modify the experimentally determined value.

The damage parameter likewise requires a number of empirically determined parameters of which the physical significance is unclear. As mentioned above, many of the more recent CZM approaches use a damage parameter based on a fracture mechanics growth relation. Thus all of the shortcomings of these relations, as discussed in section 4, are also applicable to these CZM approaches.

The main advantages of the CZM approach are that it avoids the need for re-meshing along a pre-defined crack path [183, 185, 188], and can include the initiation phase in the model [183, 190, 191]. The fracture mechanics methods discussed in section 4 can only model delamination growth. Little use seems to be made of these advantages however. In the papers discussed above the delamination size was always onedimensional, implying a straight delamination front. For these cases evaluating the growth by calculating the SERR for a number of fixed delamination lengths and integrating the $d a / d N$ vs SERR relation can be done just as readily (e.g. [61-63]). The advantageous behaviour of the CZM would be more visible in the investigation of delamination growth that is non-uniform along the delamination front, or in the investigation of planar delamination growth. The authors could not find any papers reporting such investigations in the literature though.

Similarly, although the CZM can potentially model both initiation and delamination growth using the same formulation, so far the only works making use of this feature of the CZM are those of Khoramishad et al. [190] and May, Hallett and co-workers [191-193]. Khoramishad et al. present two load-life curves [190], which include the initiation life. Due to the large scatter bands and low number of specimens in the experimental results the quality of the prediction is difficult to judge however. May et al. presented a validation [193] of the May-Hallet model [191, 192]. In this validation May et al. used the May-Hallet model to predict S-N curves for matrix cracking in two different carbon/epoxy layups. The agreement between the predicted and experimental fatigue lives was quite good, especially considering the scatter in the experimental values. It would be interesting to see whether the May-Hallet model can also correctly predict the $a$ vs $N$ behaviour in a specimen in which there is both an initiation period and significant fatigue driven delamination growth. Being able to correctly predict $a$ vs $N$ is such a case would be an important milestone towards a model capable of predicting delamination growth in in-service structures.

Moroni and Pirondi [188] have compared the CZM with the pure fracture mechanics approach, which they labelled the analytical approach. In their results the $d a / d N$ vs $G$ curves are identical for the CZM and "analytical" approaches. The $a$ vs $N$ curves exhibit some differences however. As the scenarios investigated by Moroni and Pirondi started with an initial crack, this indicates that the difference between the CZM and fracture mechanics approach lies merely in the calculation of the SERR; i.e. for the same crack length the two approaches will produce slightly different values for the SERR. Without comparing both the CZM and the fracture mechanics approach with experimental data it can not be ascertained whether the CZM approach or the fracture mechanics approach (based on the VCCT for the SERR calculation) produces a better delamination growth prediction. 


\section{Extended Finite Element Method}

The extended finite element method (XFEM) is a "meshless" finite element technique that allows more flexible modelling of crack growth. In contrast to the traditional finite element method or CZMs, using XFEM the crack path is not confined to element edges or to special interface elements. Instead enrichment functions are added to certain nodes, which allows the crack to grow arbitrarily through the element, rather than just along the edge. Thus crack growth can be simulated without the need to predefine a crack path or crack plane.

The XFEM was first proposed by Belytschko and Black [9], based on the concept of partition of unity formulated by Melenk and Babuška [194], and Duarte and Oden [195]. Belytschko and Black showed the potential of their method by numerically simulating a turning crack, though no experimental validation was offered. Moës et al. [196] refined the method described in reference [9] to deal with long and/or 3D cracks and presented a number of numerical results. Wells and Sluys [197] provided a similar demonstration, though again without a comparison to experimental data.

To also model cohesive cracking it is possible to include a cohesive law governing the traction-separation behaviour of the crack opening into the XFEM formulation, as first proposed by Moës and Belytschko [198]. Over the course of the first decade of the $21^{\text {st }}$ century further refinements of the XFEM have been devised. These developments have been summarised by Huynh and Belytschko [199].

In the last few years a number of investigations have been performed on more practical problems. Iarve et al. [200] modeled the interaction between matrix cracking and delamination in composites; Campilho et al. [201] considered fracture in adhesive joints; Curiel Sosa and Karapurath [202] investigated delamination in FMLs. All three papers mentioned provide a comparison with experimental results, with fair to good correlation between the model prediction and the experimental data. However in the paper of Campilho et al. [201] the validation is tautological, as the experimental data had also been used to generate the model inputs. The other two papers do not provide enough information on the source of the model inputs to determine whether the validation was done propperly in this case.

Recently Ling et al. [203] have shown that a CZM can also be intergrated into an augmented finite element method (A-FEM). A-FEM is a method that was first proposed by Hansbo and Hansbo [204, 205]. Although it uses a different formulation, it is equivalent to the XFEM [206].

So far nearly all the XFEM models that have been reported in literature have only considered quasistatic delamination growth. A number of XFEM approaches have included a cohesive law formulation $[198,200,201]$. By combining these formulations with a suitable damage parameter, as done in regular CZM approaches, it should be possible to model fatigue delamination growth using the XFEM. Such an attempt has not been reported in literature up to now however. Very recently an XFEM approach was developed by Bhattacharya et al. [207] for fatigue crack growth along the interface in a bi-layered material. This approach is based on the use of the Paris relationship in the original form (i.e. based on the SIF, equation 6). Due to the difficulty of calculating the SIF in a composite material, such an approach may be less suitable for delamination growth within a composite. Alternatively Bacarreza and Aliabadi have proposed a method [208] in which XFEM is used to find the delamination growth direction and VCCT is used to find the SERR values.

Ultimately all the XFEM-based delamination growth methods proposed so far, as well as potential future methods based on the CZMs discussed earlier, rely on a fracture mechanics model, correlating SIF or SERR with the delamination growth rate. Thus all the issues with these models that were raised in section 4 remain relevant.

\section{A note on applicability to real structures}

The vast majority of the models mentioned in this paper were developed and validated in the lab at coupon level, often using standardised specimens such as the DCB [209], and mixed mode bending (MMB) [210] specimens. As a result these models only describe 1D delamination growth, in a known direction. In contrast, in a real structure delamination will often be in $2 \mathrm{D}$, or even in $3 \mathrm{D}$, if one considers the phenomenon of ply-jumping. In addition the specimens under consideration in the developments of the discussed models 
are usually flat, whereas real structures, especially in aviation, are often singly or doubly curved. Some steps have already been taken towards bridiging the gap between laboratory specimens and real structures, with investigations on delamination initiation and growth in the presence of a hole [58], or following an impact [59]. Others have investigated the growth of circular delaminations [60], or of stacking sequence or fibre orientation $[71,72]$. It is clear that much work still needs to be done to transfer the knowledge gained in the lab to real situations however.

\section{Conclusions and recommendations for future research}

Over the past forty years a great variety of models has been proposed for delamination growth due to fatigue loading. Starting from the Paris relation for fatigue crack growth in metals, the first class of methods to be developed were those based on LEFM. More recently these have been complemented by models based on the CZM or XFEM approach, which also remain partly based on fracture mechanics. No matter the class of method however, these methods are almost invariably phenomenological, based on observed macroscale material behaviour and not on an understanding of the micro-mechanics underlying the delamination growth. At their core, most methods proposed for the prediction of delamination growth, even those based on the CZM, are modifications of the basic Paris relation (equation 7). Modifications of this relation are proposed, not based on a consideration of the physics of the problem, but on the observed shape of the delamination growth curve. As these models include several parameters that must be determined by curve fitting, a wide array of variations can be fit to experimental data, especially if a limited dataset is used. This disguises the lack of understanding of the physical processes. We suggest that future efforts should not focus not on adding yet more variations on the Paris relation to the collection of models that can be fit to experimental data. Instead they should concentrate on elucidating the link between the physical processes involved in delamination growth and the resultant macroscopic behaviour.

When a new equation describing delamination growth is proposed, its form should follow from a consideration of the physical mechanisms. Fractographic investigations may assist by elucidating which mechanisms are at work, and under what conditions other mechanisms may be activated, or become dominant. An illustrative example is the work of Khan [211], where a quantitative examination of fractographic features suggested that the monotonic (i.e. $G_{\max }$ ) and cyclic (i.e. $\Delta \sqrt{G}$ components of the SERR should be superimposed to predict the delamination growth rate. The resulting equation showed a very good correlation with delamination growth data from the literature [123].

Care should be taken that the driving force for delamination growth is correctly described. For example using only $G_{\max }$ or only $\Delta G$ does not provide a complete description of a fatigue cycle. The use of the SERR to predict delamination growth implies an energy balance, where the SERR is a measure for the input energy. Delamination growth (along with other mechanisms, e.g. plasticity) consume this energy. A more careful consideration of the energy balance during delamination growth may lead to a greater understanding of the delamination process and by what variables it is governed. Finally, a greater understanding of fatigue processes in bulk resin may also lead to greater understanding of delamination growth, which often proceeds by cracking of the matrix resin along a resin rich interface.

Only by a consideration of the physical processes can a true understanding of fatigue delamination growth be achieved.

\section{Acknowledgement}

This work was supported by the Netherlands Organisation for Scientific Research (NWO) by a grant from the Mosaic program under project number 017.009.005.

\section{References}

[1] J. Degrieck, W. Van Paepegem, Fatigue damage modeling of fibre-reinforced composite materials: Review, Appl Mech Rev 54 (4) (2001) 279-299. 
[2] M. Hojo, K. Tanaka, C. G. Gustafson, R. Hayashi, Effect of stress ratio on near-threshold propagation of delimination fatigue cracks in unidirectional CFRP, Compos Sci Technol 29 (4) (1987) 273-292.

[3] M. Hojo, S. Ochiai, C.-G. Gustafson, K. Tanaka, Effect of matrix resin on delamination fatigue crack growth in CFRP laminates, Eng Fract Mech 49 (1) (1994) 35-47.

[4] M. Hojo, S. Matsuda, B. Fiedler, T. Kawada, K. Moriya, S. Ochiai, H. Aoyama, Mode I and II delamination fatigue crack growth behavior of alumina fiber/epoxy laminates in liquid nitrogen, Int J Fatigue 24 (2-4) (2002) 109-118.

[5] O. Volkersen, Die Niektraftverteilung in zugbeanspruchten Nietverbindungen mit konstanten Laschenquerschritten, Luftfahrtforschung 15 (1938) 41-47.

[6] G. Roderick, R. Everett, J. Crews Jr, Debond propagation in composite reinforced metals, Tech. Rep. NASA TM X-71948, NASA (1974).

[7] S. Mostovoy, E. Ripling, Flaw Tolerance of a Number of Commercial and Experimental Adhesives, Polymer Science and Technology 9B, Plenum Press, New York, 1975, pp. 513-562.

[8] A. Needleman, A continuum model for void nucleation by inclusion debonding, J Appl Mech 54 (3) (1987) $525-531$.

[9] T. Belytschko, T. Black, Elastic crack growth in finite elements with minimal remeshing, Int J Numer Methods Eng 45 (5) (1999) 601-620.

[10] D. Gleich, Stress analysis of structural bonded joints, Phd thesis, TU Delft (2002).

[11] J. Schijve, Fatigue of Structures and Materials, 2nd Edition, Springer, Delft, 2009.

[12] J. W. Renton, J. R. Vinson, On the behavior of bonded joints in composite material structures, Eng Fract Mech 7 (1) (1975) 41-60.

[13] A. Liniecki, T. R. Hsu, W. Li, Fatigue strength of adhesive bonded aluminum joints, J Test Eval 23 (6) (1995) $453-468$.

[14] M. Imanaka, T. Iwata, Fatigue failure criterion of adhesively-bonded joints under combined stress conditions, J Adhes 59 (1-4) (1996) 111-126.

[15] M. Imanaka, T. Iwata, Effect of adhesive layer thickness on fatigue strength of adhesively bonded butt, scarf and butterfly type butt joints, Int J Fract 80 (4) (1996) R69-R76.

[16] K. Ishii, M. Imanaka, H. Nakayama, H. Kodama, Evaluation of the fatigue strength of adhesively bonded CFRP/metal single and single-step double-lap joints, Compos Sci Technol 59 (11) (1999) 1675-1683.

[17] M. Ratwani, H. P. Kan, Compression fatigue analysis of fiber composites, J Aircraft 18 (6) (1981) 458-462.

[18] A. Poursartip, N. Chinatambi, Fatigue damage development in notched $\left(0_{2} / \pm 45\right)_{s}$ laminates, in: P. A. Lagace (Ed.), Composite Materials: Fatigue and Fracture, Second Volume, ASTM STP 1012, American Society for Testing and Materials, Philadelphia, 1989, pp. 45-65.

[19] D. Broek, Elementary Engineering Fracture Mechanics, 3rd Edition, Martinus Nijhoff, The Hague, 1982.

[20] E. Rybicki, M. Kanninen, A finite element calculation of stress intensity factors by a modified crack closure integral, Eng Fract Mech 9 (4) (1977) 931-938.

[21] R. Krueger, The virtual crack closure technique: History, approach and applications, Tech. Rep. NASA/CR-2002-211628, NASA (2002).

[22] P. Paris, M. Gomez, W. Anderson, A rational analytic theory of fatigue, The Trend in Engineering 13 (1961) 9-14.

[23] P. Paris, The fracture mechanics approach to fatigue, in: 10th Sagamore Army Materials Research Conference, Syracuse University Press, 1964, pp. 107-132.

[24] P. Paris, F. Erdogan, A critical analysis of crack propagation laws, J Basic Eng 85 (4) (1963) $528-533$.

[25] R. Jones, S. Pitt, A. J. Bunner, D. Hui, Application of the Hartman-Schijve equation to represent mode I and mode II fatigue delamination growth in composites, Compos Struct 94 (4) (2012) 1343-1351.

[26] G. R. Irwin, Analysis of stresses and strains near the end of a crack traversing a plate, ASME Journal of Applied Mechanics 24 (1957) 361-364.

[27] G. C. Sih, P. C. Paris, G. R. Irwin, On cracks in rectilinearly anisotropic bodies, Int J Fract 1 (3) (1965) $189-203$.

[28] C. Rans, R. C. Alderliesten, R. Benedictus, Misinterpreting the results: How similitude can improve our understanding of fatigue delamination growth, Compos Sci Technol 71 (2011) 230-238.

[29] G. L. Roderick, R. A. Everett Jr., J. H. Crews Jr, Cyclic debonding of unidirectional composite bonded to aluminum sheet for constant-amplitude loading, Tech. Rep. NASA TN D-8126, NASA (1976).

[30] P. Paris, G. Sih, Stress analysis of cracks, in: Fracture Toughness Testing and its Applications, ASTM STP 381, American Society for Testing and Materials, pp. 30-83.

[31] S. Mall, W. S. Johnson, R. A. Everett Jr., Cyclic debonding of adhesively bonded composites, Tech. Rep. NASA TM84577, NASA (1982).

[32] R. A. Everett Jr., The role of peel stresses in cyclic debonding, Tech. Rep. NASA-TM-84504, NASA (1982).

[33] R. A. Everett Jr., W. S. Johnson, Repeatability of mixed-mode adhesive debonding, Tech. Rep. NASA TM-85753, NASA (1984).

[34] B. Dattaguru, J. R. A. Everett, J. D. Whitcomb, W. S. Johnson, Geometrically nonlinear analysis of adhesively bonded joints, J Eng Mater Technol 106 (1) (1984) 59-65.

[35] S. Mall, W. S. Johnson, Characterization of mode I and mixed-mode failure of adhesvie bonds between composite adherends, Tech. Rep. NASA TM-86355, NASA (1985).

[36] W. Johnson, S. Mall, A fracture mechanics approach for designing adhesively bonded joints, in: W. Johnson (Ed.), Delamination and Debonding of Materials, ASTM STP 876, American Society for Testing and Materials, Philadelphia, 1985, pp. 189-199.

[37] M. A. Rezaizadeh, S. Mall, Mixed-mode cyclic debonding of adhesively bonded composite joints, Tech. Rep. NASA CR-177991, NASA (1985).

[38] P. D. Mangalgiri, W. S. Johnson, R. A. Everett, Effect of adherend thickness and mixed mode loading on debond growth 
in adhesively bonded composite joints, J Adhes 23 (4) (1987) 263-288.

[39] D. A. Jablonski, Fatigue crack growth in structural adhesives, J Adhes 11 (2) (1980) 125-143.

[40] T. R. Brussat, S. T. Chiu, S. Mostovoy, Fracture mechanics for structural adhesive bonds - final report, Tech. Rep. AFML-TR-77-163, US Air Force Materials Laboratory (1977).

[41] T. R. Brussat, S. T. Chiu, Fatigue crack growth of bondline cracks in structural bonded joints, J Eng Mater Technol 100 (1) (1978) 39-45.

[42] S. S. Wang, H. T. Wang, Interlaminar crack growth in fiber reinforced composites during fatigue, J Eng Mater Technol 101 (1) (1979) 34-41.

[43] T. O'Brien, Characterization of delamination onset and growth in a composite laminate, Tech. Rep. NASA Technical Memorandum 81940, NASA (1981).

[44] T. K. O'Brien, Characterization of delamination onset and growth in a composite laminate, in: K. Reifsnider (Ed.), Damage in Composite Materials, ASTM STP 775, American Society for Testing and Materials, Philadelphia, 1982, pp. $140-167$.

[45] D. Wilkins, J. Eisenmann, R. Camin, W. Margolis, R. Benson, Characterizing delamination growth in graphite-epoxy, in: K. Reifsnider (Ed.), Damage in Composite Materials, ASTM STP 775, American Society for Testing and Materials, pp. $168-183$.

[46] A. Wang, M. Slomiana, R. Bucinell, Delamination crack growth in composite laminates, in: W. Johnson (Ed.), Delamination and Debonding of Materials, ASTM STP 876, American Society for Testing and Materials, Philadelphia, 1985, pp. $135-167$.

[47] G. E. Dieter, Mechanical Metallurgy, second edition Edition, McGraw-Hill Series in Materials Science and Engineering, McGraw-Hill Book Company, New York, 1976.

[48] T. Mohlin, A. Blom, L. Carlsson, A. Gustavsson, Delamination growth in a notched graphite/epoxy laminate under compression fatigue loading, in: W. Johson (Ed.), Delamination and Debonding of Materials, ASTM STP 876, American Society for Testing and Materials, Philadelphia, 1985, pp. 168-188.

[49] C. Bathias, A. Laksimi, Delamination threshold and loading effect in fiber glass epoxy composite, in: W. Johnson (Ed.), Delamination and Debonding of Materials, ASTM STP 876, American Society for Testing and Materials, Philadelphia, 1985, pp. 217-237.

[50] C.-G. Gustafson, M. Hojo, Delamination fatigue crack growth in unidirectional graphite/epoxy laminates, J Reinf Plast Compos 6 (1) (1987) 36-52.

[51] N. Dowling, J. Begley, Fatigue crack growth during gross plasticity and the J-integral, in: Mechanics of Crack Growth, ASTM STP 590, American Society for Testing and Materials, 1976, pp. 82-103.

[52] A. G. Thomas, Rupture of rubber. V. Cut growth in natural rubber vulcanizates, J Polym Sci 31 (123) (1958) 467-480.

[53] K. Kageyama, I. Kimpara, I. Ohsawa, M. Hojo, S. Kabashima, Mode I and mode II delamination growth of interlayer toughened carbon/epoxy $(\mathrm{T} 800 \mathrm{H} / 39002)$ composite system, in: R. H. Martin (Ed.), Composite Materials: Fatigue and Fracture - Fifth Volume, ASTM STP 1230, American Society of Testing and Materials, Philadelphia, 1995 , pp. $19-37$.

[54] K. Kageyama, I. Kimpara, T. Suzuki, I. Ohsawa, K. Esaki, Effect of interleaf thickness of mode II fatigue delamination growth of interleaved carbon/epoxy, Key Eng Mater 137 (1998) 187-194.

[55] M. Hojo, S. Matsuda, M. Tanaka, S. Ochiai, A. Murakami, Mode I delamination fatigue properties of interlayer-toughened CF/epoxy laminates, Compos Sci Technol 66 (5) (2006) 665-675.

[56] F. Aymerich, R. Onnis, P. Priolo, Analysis of the effect of stitching on the fatigue strength of single-lap composite joints, Compos Sci Technol 66 (2) (2006) 166-175.

[57] M. Hojo, K. Nakashima, T. Kusaka, M. Tanaka, T. Adachi, T. Fukuoka, M. Ishibashi, Mode I fatigue delamination of Zanchor-reinforced CF/epoxy laminates, Int J Fatigue 32 (1) (2010) 37-45.

[58] M. Beghini, L. Bertini, E. Vitale, Analysis of fatigue delamination growth in carboresin specimens with central hole, Compos Struct 17 (3) (1991) 257-274.

[59] D. G. Katerelos, A. Paipetis, V. Kostopoulos, A simple model for the prediction of the fatigue delamination growth of impacted composite panels, Fatigue Fract Eng Mater Struct 27 (10) (2004) 911-922.

[60] S. C. Pradhan, T. E. Tay, Three-dimensional finite element modelling of delamination growth in notched composite laminates under compression loading, Eng Fract Mech 60 (2) (1998) 157-171.

[61] R. Krueger, Development of a benchmark example for delamination fatigue growth prediction, Tech. Rep. NASA/CR2010-216723 / NIA Report No. 2010-04, NASA / NIA (2010).

[62] R. Krueger, Development of benchmark examples for delamination onset and fatigue growth prediction, Tech. Rep. NF1676L-11493, NASA (2011).

[63] R. Krueger, Development of benchmark examples for static delamination propagation and fatigue growth predictions, Tech. Rep. NF1676L-11356, NASA (2011).

[64] A. Hosoi, Y. Arao, H. Karasawa, H. Kawada, High-cycle fatigue characteristics of quasi-isotropic CFRP laminates, Adv Compos Mater 16 (2) (2007) 151-166.

[65] A. Hosoi, N. Sato, Y. Kusumoto, K. Fujiwara, H. Kawada, High-cycle fatigue characteristics of quasi-isotropic CFRP laminates over $10^{8}$ cycles (initiation and propagation of delamination considering interaction with transverse cracks), Int J Fatigue 32 (1) (2010) 29-36.

[66] A. Hosoi, K. Takamura, N. Sato, H. Kawada, Quantitative evaluation of fatigue damage growth in CFRP laminates that changes due to applied stress level, Int J Fatigue 33 (6) (2011) 781-787.

[67] A. Russell, K. Street, The effect of matrix toughness on delamination: Static and fatigue fracture under mode II shear loading of graphite fiber composites, in: N. J. Johnston (Ed.), Toughened Composites, ASTM STP 937, American Society for Testing and Materials, Philadelphia, 1987, pp. 275-294. 
[68] M. N. Bureau, J. Denault, Fatigue behavior of continuous glass fiber composites: Effect of the matrix nature, Polym Compos 21 (4) (2000) 636-644.

[69] M. N. Bureau, F. Perrin, J. Denault, J. I. Dickson, Interlaminar fatigue crack propagation in continuous glass fiber/polypropylene composites, Int J Fatigue 24 (2-4) (2002) 99-108.

[70] Y. Prel, P. Davies, M. Benzeggagh, F.-X. de Charentenay, Mode I and mode II delamination of thermosetting and thermoplastic composites, in: P. A. Lagace (Ed.), Composite Materials: Fatigue and Fracture, Second Volume, ASTM STP 1012, American Society for Testing and Materials, Philadelphia, 1989, pp. 251-269.

[71] S. Ogihara, N. Takeda, S. Kobayashi, A. Kobayashi, Effects of stacking sequence on microscopic fatigue damage development in quasi-isotropic CFRP laminates with interlaminar-toughened layers, Compos Sci Technol 59 (9) (1999) $1387-1398$.

[72] M. Beghini, L. Bertini, P. Forte, Experimental investigation on the influence of crack front to fiber orientation on fatigue delamination growth rate under mode II, Compos Sci Technol 66 (2) (2006) 240-247.

[73] R. Marissen, Fatigue crack growth in ARALL. a hybrid aluminium-aramid composite material: Crack growth mechanisms and quantitative predictions of the crack growth rates, Ph.D. thesis, Delft University of Technology (1988).

[74] S. Zhao, M. Gadke, R. Prinz, Mixed-mode delamination behavior of carbon/epoxy composites, J Reinf Plast Compos 14 (8) (1995) 804-826.

[75] R. C. Alderliesten, Fatigue crack propagation and delamination growth in glare, Ph.D. thesis, Delft University of Technology (2005).

[76] R. C. Alderliesten, J. Schijve, S. van der Zwaag, Application of the energy release rate approach for delamination growth in Glare, Eng Fract Mech 73 (6) (2006) 697-709.

[77] G. Matsubara, H. Ono, K. Tanaka, Mode II fatigue crack growth from delamination in unidirectional tape and satin-woven fabric laminates of high strength GFRP, Int J Fatigue 28 (10) (2006) 1177-1186.

[78] R. H. Martin, G. B. Murri, Characterization of mode I and mode II delamination growth and thresholds in graphite/PEEK composites, Tech. Rep. Technical Memorandum 100577, NASA (1988).

[79] R. H. Martin, G. B. Murri, Characterization of mode I and mode II delamination growth and thresholds in AS4/PEEK composites, in: S. Garbo (Ed.), Composite Materials: Testing and Design (Ninth Volume), ASTM STP 1059, American Society for Testing and Materials, Philadelphia, 1990, pp. 251-270.

[80] W. Elber, The significance of fatigue crack closure, in: Damage Tolerance in Aircraft Structures, ASTM STP 486, American Society for Testing and Materials, 1971, pp. 230-242.

[81] S. Singh, E. Greenhalgh, Delamination growth in epoxy-matrix composites under cyclic loading: implications for design and certification, in: 8th European Conference on Composite Materials (ECCM-8), Naples, 1998.

[82] S. Mall, G. Ramamurthy, M. A. Rezaizdeh, Stress ratio effect on cyclic debonding in adhesively bonded composite joints, Compos Struct 8 (1) (1987) 31-45.

[83] W. Chan, A. Wang, Free-edge delamination characteristics in S2/CE9000 glass/epoxy laminates under static and fatigue loads, in: P. A. Lagace (Ed.), Composite Materials: Fatigue and Fracture, Second Volume, ASTM STP 1012, American Society for Testing and Materials, Philadelphia, 1989, pp. 270-295.

[84] G. Allegri, M. I. Jones, M. R. Wisnom, S. R. Hallett, A new semi-empirical model for stress ratio effect on mode II fatigue delamination growth, Composites Part A 42 (7) (2011) 733-740.

[85] J. Andersons, M. Hojo, S. Ochiai, Model of delamination propagation in brittle-matrix composites under cyclic loading, J Reinf Plast Compos 20 (5) (2001) 431-450.

[86] M. Hojo, T. Ando, M. Tanaka, T. Adachi, S. Ochiai, Y. Endo, Modes I and II interlaminar fracture toughness and fatigue delamination of CF/epoxy laminates with self-same epoxy interleaf, Int J Fatigue 28 (10) (2006) 1154-1165.

[87] C. T. Lin, P. W. Kao, Fatigue delamination growth in carbon fibre-reinforced aluminium laminates, Composites Part A 27 (1) (1996) 9-15.

[88] J. Andersons, M. Hojo, S. Ochiai, Empirical model for stress ratio effect on fatigue delamination growth rate in composite laminates, Int J Fatigue 26 (6) (2004) 597-604.

[89] L. F. Kawashita, M. I. Jones, R. S. Trask, S. R. Hallett, M. R. Wisnom, Static and fatigue delamination from discontinuous plies - experimental and numerical investigations, in: 17th International conference on composite materials (ICCM17), IOM communications Ltd., 2009.

[90] D. R. Atodaria, S. K. Putatunda, P. K. Mallick, A fatigue crack growth model for random fiber composites, J Compos Mater 31 (18) (1997) 1838-1855.

[91] D. R. Atodaria, S. K. Putatunda, P. K. Mallick, Delamination growth behavior of a fabric reinforced laminated composite under mode I fatigue, J Eng Mater Technol 121 (3) (1999) 381-385.

[92] D. R. Atodaria, S. K. Putatunda, P. K. Mallick, Fatigue crack growth model and mechanism of a random fiber SMC composite, Polym Compos 20 (2) (1999) 240-249.

[93] M. Klesnil, P. Lukáš, Effect of stress cycle asymmetry on fatigue crack growth, Materials Science and Engineering 9 (0) (1972) 231-240.

[94] A. Hartman, J. Schijve, The effects of environment and load frequency on the crack propagation law for macro fatigue crack growth in aluminium alloys, Eng Fract Mech 1 (4) (1970) 615-631.

[95] S. Donaldson, S. Mall, Delamination growth in graphite/epoxy composites subjected to cyclic mode III loading, J Reinf Plast Compos 8 (1) (1989) 91-103.

[96] N. Blanco Villaverde, Variable mixed-mode delamination in composite laminates under fatigue conditions: testing \& analysis, Ph.D. thesis, Universitat de Girona (2004).

[97] N. Blanco, E. K. Gamstedt, L. E. Asp, J. Costa, Mixed-mode delamination growth in carbon-fibre composite laminates under cyclic loading, Int J Solids Struct 41 (15) (2004) 4219-4235. 
[98] K. Liechti, W. Knauss, Crack propagation at material interfaces: II experiments on mode interaction, Exp Mech 22 (10) (1982) 383-391.

[99] X. X. Xu, A. D. Crocombe, P. A. Smith, Mixed-mode fatigue and fracture behaviour of joints bonded with either filled or filled and toughened adhesive, Int J Fatigue 17 (4) (1995) 279-286.

[100] R. Ramkumar, J. Whitcomb, Characterization of mode I and mixed-mode delamination growth in T300/5208 graphite/expoxy, in: W. Johnson (Ed.), Delamination and Debonding of Materials, ASTM STP 876, American Society for Testing and Materials, Philadelphia, 1985, pp. 315-335.

[101] A. Russell, K. Street, Predicting interlaminar fatigue crack growth rate in compressively loaded laminates, in: P. A. Lagace (Ed.), Composite Materials: Fatigue and Fracture, Second Volume, ASTM STP 1012, Philadelphia, Philadelphia, 1989, pp. $162-178$.

[102] M. Kenane, M. L. Benzeggagh, Mixed-mode delamination fracture toughness of unidirectional glass/epoxy composites under fatigue loading, Compos Sci Technol 57 (5) (1997) 597-605.

[103] G. A. Kardomateas, A. A. Pelegri, B. Malik, Growth of internal delaminations under cyclic compression in composite plates, J Mech Phys Solids 43 (6) (1995) 847-868.

[104] G. A. Kardomateas, Predicting the growth of internal delaminations under monotonic or cyclic compression, Vol. 120-121, 1996, pp. 441-462.

[105] G. A. Kardomateas, B. Malik, Fatigue delamination growth under cyclic compression in glass/epoxy composite beam/plates, Polym Compos 18 (2) (1997) 169-178.

[106] J. W. Hutchinson, Z. Suo, Mixed mode cracking in layered materials, in: W. H. John, Y. W. Theodore (Eds.), Advances in Applied Mechanics, Vol. 29, Elsevier, pp. 63-191.

[107] L. E. Asp, A. Sjögren, E. Greenhalgh, Delamination growth and thresholds in a carbon/epoxy composite under fatigue loading., J Compos Tech Res 23 (2) (2001) 55-68.

[108] M. Quaresimin, M. Ricotta, Stress intensity factors and strain energy release rates in single lap bonded joints in composite materials, Compos Sci Technol 66 (5) (2006) 647-656.

[109] M. Quaresimin, M. Ricotta, Life prediction of bonded joints in composite materials, Int J Fatigue 28 (10) (2006) 11661176.

[110] S. Singh, E. Greenhalgh, Micromechanisms of interlaminar fracture in carbon-epoxy composites at multidirectional ply interfaces, in: 4th International Conference on the Deformation and Fracture of Composites (DFC-4), 1997.

[111] T. K. O'Brien, Composite interlaminar shear fracture toughness, GIIc: Shear measurement or sheer myth?, in: R. B. Bucinell (Ed.), Composite Materials: Fatigue and Fracture, 7th Volume, ASTM STP 1330, 1998, pp. 3-18.

[112] H. Chai, Shear fracture, Int J Fract 37 (2) (1988) 137-159.

[113] H. Chai, Experimental evaluation of mixed-mode fracture in adhesive bonds, Exp Mech 32 (4) (1992) 296-303.

[114] G. Allegri, M. R. Wisnom, A non-linear damage evolution model for mode II fatigue delamination onset and growth, Int J Fatigue 43 (0) (2012) 226-234.

[115] A. Poursartip, The characterization of edge delamination growth in laminates under fatigue loading, in: N. J. Johnston (Ed.), Toughened Composites, ASTM STP 937, American Society for Testing and Materials, Philadelphia, 1987, pp. $222-241$.

[116] K. Shivakumar, H. Chen, F. Abali, D. Le, C. Davis, A total fatigue life model for mode I delaminated composite laminates, Int J Fatigue 28 (1) (2006) 33-42.

[117] H. Chen, K. Shivakumar, F. Abali, A comparison of total fatigue life models for composite laminates, Fatigue Fract Eng Mater Struct 29 (1) (2006) 31-39.

[118] L. Peng, J. Zhang, L. Zhao, R. Bao, H. Yang, B. Fei, Mode I delamination growth of multidirectional composite laminates under fatigue loading, J Compos Mater 45 (10) (2011) 1077-1090.

[119] J. Zhang, L. Peng, L. Zhao, B. Fei, Fatigue delamination growth rates and thresholds of composite laminates under mixed mode loading, Int J Fatigue 40 (2012) 7-15.

[120] S. Giannis, K. Hansen, R. H. Martin, Accounting for the R-curve effects on the mode I fatigue delamination growth characterisation of unidirectional composites, in: 5th Annual Technical Conference of the American Society for Composites, Dayton, Ohio, Vol. 2, 2010, pp. 983-1000.

[121] G. B. Murri, Evaluation of delamination onset and growth characterization methods under mode I fatigue loading, in: American Society for Composites, 27th Technical Conference, DEStech Publications, Inc., Arlington,TX, 2012, pp. $601-620$.

[122] G. B. Murri, Evaluation of delamination onset and growth characterization methods under mode I fatigue loading, Tech. Rep. NASA/TM-2013-217966, NASA (2013).

[123] R. C. Alderliesten, Critical review on the evaluation of delamination resistance in composites, in: $9^{\text {th }}$ International Conference on Composite Science and Technology, 2013.

[124] A. Sjögren, L. E. Asp, Effects of temperature on delamination growth in a carbon/epoxy composite under fatigue loading, Int J Fatigue $24(2-4)(2002)$ 179-184.

[125] Y. Shindo, A. Inamoto, F. Narita, K. Horiguchi, Mode I fatigue delamination growth in GFRP woven laminates at low temperatures, Eng Fract Mech 73 (14) (2006) 2080-2090.

[126] Y. Shindo, T. Takeda, F. Narita, N. Saito, S. Watanabe, K. Sanada, Delamination growth mechanisms in woven glass fiber reinforced polymer composites under mode II fatigue loading at cryogenic temperatures, Compos Sci Technol 69 (11-12) (2009) 1904-1911.

[127] Y. Shindo, M. Miura, T. Takeda, N. Saito, F. Narita, Cryogenic delamination growth in woven glass/epoxy composite laminates under mixed-mode I/II fatigue loading, Compos Sci Technol 71 (5) (2011) 647-652.

[128] P. Coronado, A. Argüelles, J. Viña, V. Mollón, I. Viña, Influence of temperature on a carbon-fibre epoxy composite 
subjected to static and fatigue loading under mode I delamination, Int J Solids Struct 49 (21) (2012) 2934-2940.

[129] D. A. Burianek, S. M. Spearing, Delamination growth from face sheet seams in cross-ply titanium/graphite hybrid laminates, Compos Sci Technol 61 (2) (2001) 261-269.

[130] C. D. Rans, R. C. Alderliesten, R. Benedictus, Predicting the influence of temperature on fatigue crack propagation in fibre metal laminates, Eng Fract Mech 78 (10) (2011) 2193-2201.

[131] I. A. Ashcroft, D. J. Hughes, S. J. Shaw, M. A. Wahab, A. Crocombe, Effect of temperature on the quasi-static strength and fatigue resistance of bonded composite double lap joints, J Adhes 75 (1) (2001) 61-88.

[132] I. A. Ashcroft, S. J. Shaw, Mode I fracture of epoxy bonded composite joints 2. Fatigue loading, Int J Adhes Adhes 22 (2) (2002) 151-167.

[133] G. Hartwig, S. Knaak, Fibre-epoxy composites at low temperatures, Cryogenics 24 (11) (1984) 639-647.

[134] A. Russell, K. Street, Moisture and temperature effects on the mixed-mode delamination fracture of unidirectional graphite/epoxy, in: W. S. Johnson (Ed.), Delamination and Debonding of Materials, ASTM STP 876, American Society for Testing and Materials, Philadelphia, pp. 349-370.

[135] M. Hojo, K. Tanaka, C.-G. Gustafson, R. Hayashi, Fracture mechanics for delamination fatigue crack propagation of CFRP in air and in water, Mechanical and corrosion properties Series A, Key engineering materials 37 (1989) 149-160.

[136] M. Fernando, W. W. Harjoprayitno, A. J. Kinloch, A fracture mechanics study of the influence of moisture on the fatigue behaviour of adhesively bonded aluminium-alloy joints, Int J Adhes Adhes 16 (2) (1996) 113-119.

[137] J. K. Jethwa, A. J. Kinloch, The fatigue and durability behaviour of automotive adhesives. part I: Fracture mechanics tests, J Adhes 61 (1-4) (1997) 71-95.

[138] R. A. Dickie, L. P. Haack, J. K. Jethwa, A. J. Kinloch, J. F. Watts, The fatigue and durability behaviour of automotive adhesives. part II: Failure mechanisms, J Adhes 66 (1-4) (1998) 1-37.

[139] B. Landry, G. LaPlante, L. R. LeBlanc, Environmental effects on mode II fatigue delamination growth in an aerospace grade carbon/epoxy composite, Composites Part A 43 (3) (2012) 475-485.

[140] A. J. Kinloch, S. O. Osiyemi, Predicting the fatigue life of adhesively-bonded joints, J Adhes 43 (1-2) (1993) 79-90.

[141] A. J. Curley, H. Hadavinia, A. J. Kinloch, A. C. Taylor, Predicting the service-life of adhesively-bonded joints, Int J Fract 103 (1) (2000) 41-69.

[142] H. Hadavinia, A. J. Kinloch, M. S. G. Little, A. C. Taylor, The prediction of crack growth in bonded joints under cyclic-fatigue loading I. Experimental studies, Int J Adhes Adhes 23 (6) (2003) 449-461.

[143] H. Hadavinia, A. J. Kinloch, M. S. G. Little, A. C. Taylor, The prediction of crack growth in bonded joints under cyclic-fatigue loading II. Analytical and finite element studies, Int J Adhes Adhes 23 (6) (2003) 463-471.

[144] M. M. Abdel Wahab, I. A. Ashcroft, A. D. Crocombe, P. A. Smith, Numerical prediction of fatigue crack propagation lifetime in adhesively bonded structures, Int J Fatigue 24 (6) (2002) 705-709.

[145] H. Chen, K. N. Shivakumar, F. Abali, Application of total fatigue life model to T700 carbon/vinyl ester composite, Composites Part B 39 (1) (2008) 36-41.

[146] ASTM Standard D6115-97, 2011, Standard test method for mode I fatigue delamination growth onset of unidirectional fiber-reinforced polymer matrix composites, ASTM International, West Conshohocken, PA, USA (2011).

[147] J. Schön, A. Blom, Fatigue life prediction and load cycle elimination during spectrum loading of composites, Int J Fatigue $24(2-4)(2002) 361-367$.

[148] R. Marissen, Fatigue crack growth in arall: A hybrid aluminium-aramid composite material: Crack growth mechanisms and quantitative predictions of the crack growth rates, Tech. Rep. LR-574, TU Delft (1988)

[149] S. U. Khan, R. C. Alderliesten, R. Benedictus, Delamination growth in fibre metal laminates under variable amplitude loading, Compos Sci Technol 69 (15-16) (2009) 2604-2615.

[150] Anonymous, Load history effects, in: Composite Materials Handbook: CMH-17 Rev G, Vol 1 section 6-9-4-8, SAE, 2012

[151] J. Schön, A model of fatigue delamination in composites, Compos Sci Technol 60 (4) (2000) 553-558.

[152] M. Kenane, S. Benmedakhene, Z. Azari, Fracture and fatigue study of unidirectional glass/epoxy laminate under different mode of loading, Fatigue Fract Eng Mater Struct 33 (5) (2010) 284-293.

[153] J. Schön, Model for predicting the load ratio for the shortest fatigue life, Compos Sci Technol 61 (8) (2001) 1143-1149.

[154] C. Bakis, W. Stinchcomb, Fatigue response of notched laminates subjected to tension-comperssion cyclic loads, Tech. Rep. NASA-CR-179804, Virginia Polytechnic Institute and State University / NASA (1986).

[155] C. Dahlen, G. S. Springer, Delamination growth in composites under cyclic loads, J Compos Mater 28 (8) (1994) $732-781$.

[156] E. Buckingham, On physically similar systems; illustrations of the use of dimensional equations, Phys Rev 4 (4) (1914) 345-376.

[157] G. Wimmer, H. Pettermann, Prediction of delamination growth in laminated structures loaded by quasi-static and cyclic loads, J Compos Mater 43 (26) (2009) 3303-3324.

[158] G. Wimmer, W. Kitzmüller, G. Pinter, T. Wettemann, H. E. Pettermann, Computational and experimental investigation of delamination in L-shaped laminated composite components, Eng Fract Mech 76 (18) (2009) 2810-2820.

[159] D. Xie, S. B. Biggers Jr, Strain energy release rate calculation for a moving delamination front of arbitrary shape based on the virtual crack closure technique. Part I: Formulation and validation, Eng Fract Mech 73 (6) (2006) 771-785.

[160] D. Xie, S. B. Biggers Jr, Strain energy release rate calculation for a moving delamination front of arbitrary shape based on the virtual crack closure technique. Part II: Sensitivity study on modeling details, Eng Fract Mech 73 (6) (2006) 786-801.

[161] M. Boscolo, G. Allegri, X. Zhang, Design and modeling of selective reinforcements for integral aircraft structures, AIAA J 46 (9) (2008) 2323-2331.

[162] M. Boscolo, G. Allegri, X. Zhang, Enhanced 2-D modeling technique for single-sided patch repairs, AIAA J 47 (6) (2009) $1558-1567$ 
[163] X. Zhang, M. Boscolo, D. Figueroa-Gordon, G. Allegri, P. E. Irving, Fail-safe design of integral metallic aircraft structures reinforced by bonded crack retarders, Eng Fract Mech 76 (1) (2009) 114-133.

[164] M. Boscolo, X. Zhang, A modelling technique for calculating stress intensity factors for structures reinforced by bonded straps. Part I: Mechanisms and formulation, Eng Fract Mech 77 (6) (2010) 883-895.

[165] M. Boscolo, X. Zhang, A modelling technique for calculating stress intensity factors for structures reinforced by bonded straps. Part II: Validation, Eng Fract Mech 77 (6) (2010) 896-907.

[166] D. S. Dugdale, Yielding of steel sheets containing slits, J Mech Phys Solids 8 (2) (1960) 100-104.

[167] G. I. Barenblatt, The mathematical theory of equilibrium cracks in brittle fracture, in: H. Dryden, T. v. Kármán, G. Kuerti, F. H. v. d. Dungen, L. Howarth (Eds.), Advances in Applied Mechanics, Vol. 7, Elsevier, pp. 55-129, accessed through the Defense Technical Information Centre (www.dtic.mil) under report number AD 283881.

[168] A. Needleman, An analysis of decohesion along an imperfect interface, Int J Fract 42 (1) (1990) 21-40.

[169] J. W. Hutchinson, A. G. Evans, Mechanics of materials: top-down approaches to fracture, Acta Mater 48 (1) (2000) $125-135$.

[170] P. Camanho, C. Dávila, D. Ambur, Numerical simulation of delamination growth in composite materials, Tech. Rep. NASA/TP-2001-211041, NASA (2001).

[171] K. L. Roe, T. Siegmund, An irreversible cohesive zone model for interface fatigue crack growth simulation, Eng Fract Mech 70 (2) (2003) 209-232.

[172] A. Needleman, Micromechanical modelling of interfacial decohesion, Ultramicroscopy 40 (3) (1992) $203-214$.

[173] G. T. Camacho, M. Ortiz, Computational modelling of impact damage in brittle materials, Int J Solids Struct 33 (20-22) (1996) 2899-2938.

[174] J. W. Foulk III, D. H. Allen, K. L. E. Helms, A model for predicting the damage and environmental degradation dependent life of SCS-6/Timetal 21S [0] $]_{4}$ metal matrix composite, Mech Mater 29 (1) (1998) 53-68.

[175] A. de Andrés, J. L. Pérez, M. Ortiz, Elastoplastic finite element analysis of three-dimensional fatigue crack growth in aluminum shafts subjected to axial loading, Int J Solids Struct 36 (15) (1999) 2231-2258.

[176] O. Nguyen, E. A. Repetto, M. Ortiz, R. A. Radovitzky, A cohesive model of fatigue crack growth, Int J Fract 110 (4) (2001) 351-369.

[177] B. Yang, S. Mall, K. Ravi-Chandar, A cohesive zone model for fatigue crack growth in quasibrittle materials, Int J Solids Struct 38 (22-23) (2001) 3927-3944.

[178] P. P. Camanho, C. G. Davila, M. F. de Moura, Numerical simulation of mixed-mode progressive delamination in composite materials, J Compos Mater 37 (16) (2003) 1415-1438.

[179] M. L. Benzeggagh, M. Kenane, Measurement of mixed-mode delamination fracture toughness of unidirectional glass/epoxy composites with mixed-mode bending apparatus, Compos Sci Technol 56 (4) (1996) 439-449.

[180] P. Robinson, U. Galvanetto, D. Tumino, G. Bellucci, D. Violeau, Numerical simulation of fatigue-driven delamination using interface elements, Int J Numer Methods Eng 63 (13) (2005) 1824-1848.

[181] R. H. J. Peerlings, W. A. M. Brekelmans, R. de Borst, M. G. D. Geers, Gradient-enhanced damage modelling of high-cycle fatigue, Int J Numer Methods Eng 49 (12) (2000) 1547-1569.

[182] G. Alfano, M. A. Crisfield, Finite element interface models for the delamination analysis of laminated composites: mechanical and computational issues, Int J Numer Methods Eng 50 (7) (2001) 1701-1736.

[183] J. J. Muñoz, U. Galvanetto, P. Robinson, On the numerical simulation of fatigue driven delamination with interface elements, Int J Fatigue 28 (10) (2006) 1136-1146.

[184] D. Tumino, F. Cappello, Simulation of fatigue delamination growth in composites with different mode mixtures, J Compos Mater 41 (20) (2007) 2415-2441.

[185] P. W. Harper, S. R. Hallett, A fatigue degradation law for cohesive interface elements - development and application to composite materials, Int J Fatigue 32 (11) (2010) 1774-1787.

[186] A. Turon, J. Costa, P. P. Camanho, C. G. Dávila, Simulation of delamination in composites under high-cycle fatigue, Composites Part A 38 (11) (2007) 2270-2282.

[187] A. Pirondi, F. Moroni, A progressive damage model for the prediction of fatigue crack growth in bonded joints, J Adhes $86(5-6)(2010) 501-521$.

[188] F. Moroni, A. Pirondi, A procedure for the simulation of fatigue crack growth in adhesively bonded joints based on the cohesive zone model and different mixed-mode propagation criteria, Eng Fract Mech 78 (8) (2011) 1808-1816.

[189] B. Landry, G. LaPlante, Modeling delamination growth in composites under fatigue loadings of varying amplitudes, Composites Part B 43 (2) (2012) 533-541.

[190] H. Khoramishad, A. D. Crocombe, K. B. Katnam, I. A. Ashcroft, Predicting fatigue damage in adhesively bonded joints using a cohesive zone model, Int J Fatigue 32 (7) (2010) 1146-1158.

[191] M. May, S. R. Hallett, A combined model for initiation and propagation of damage under fatigue loading for cohesive interface elements, Composites Part A 41 (12) (2010) 1787-1796.

[192] M. May, S. R. Hallett, An advanced model for initiation and propagation of damage under fatigue loading - part I: Model formulation, Compos Struct 93 (9) (2011) 2340-2349.

[193] M. May, R. Pullin, M. Eaton, C. Featherston, S. R. Hallett, An advanced model for initiation and propagation of damage under fatigue loading âĂŞ part ii: Matrix cracking validation cases, Compos Struct 93 (9) (2011) 2350-2357.

[194] J. Melenk, I. Babuška, The partition of unity finite element method, Tech. Rep. Research Report No. 1996-01, Eidgenössische Technische Hochschule, Seminar für Angewandte Mathematik (1996).

[195] C. A. Duarte, J. T. Oden, H-p clouds-an h-p meshless method, Numerical Methods for Partial Differential Equations 12 (6) (1996) 673-705.

[196] N. Moës, J. Dolbow, T. Belytschko, A finite element method for crack growth without remeshing, Int J Numer Methods 
Eng 46 (1) (1999) 131-150.

[197] G. N. Wells, L. J. Sluys, A new method for modelling cohesive cracks using finite elements, Int J Numer Methods Eng 50 (12) (2001) 2667-2682.

[198] N. Moës, T. Belytschko, Extended finite element method for cohesive crack growth, Eng Fract Mech 69 (7) (2002) 813-833.

[199] D. B. P. Huynh, T. Belytschko, The extended finite element method for fracture in composite materials, Int J Numer Methods Eng 77 (2) (2009) 214-239.

[200] E. Iarve, M. Gurvich, D. Mollenhauer, Discrete modeling of arbitrary matrix cracking and delaminations in laminated composites, in: International Conference on Composite Materials: ICCM-17.

[201] R. D. S. G. Campilho, M. D. Banea, F. J. P. Chaves, L. F. M. d. Silva, eXtended Finite Element Method for fracture characterization of adhesive joints in pure mode I, Comput Mater Sci 50 (4) (2011) 1543-1549.

[202] J. L. Curiel Sosa, N. Karapurath, Delamination modelling of glare using the extended finite element method, Compos Sci Technol 72 (7) (2012) 788-791.

[203] D. Ling, Q. Yang, B. Cox, An augmented finite element method for modeling arbitrary discontinuities in composite materials, Int J Fract 156 (1) (2009) 53-73.

[204] A. Hansbo, P. Hansbo, An unfitted finite element method, based on NitscheâĂŹs method, for elliptic interface problems, Comput Meth Appl Mech Eng 191 (47-48) (2002) 5537-5552.

[205] A. Hansbo, P. Hansbo, A finite element method for the simulation of strong and weak discontinuities in solid mechanics, Comput Meth Appl Mech Eng 193 (33-35) (2004) 3523-3540.

[206] P. M. A. Areias, T. Belytschko, A comment on the article "a finite element method for simulation of strong and weak discontinuities in solid mechanics" by A. Hansbo and P. Hansbo [Comput. Methods Appl. Mech. Engrg. 193 (2004) 3523-3540], Comput Meth Appl Mech Eng 195 (9-12) (2006) 1275-1276.

[207] S. Bhattacharya, I. V. Singh, B. K. Mishra, T. Q. Bui, Fatigue crack growth simulations of interfacial cracks in bi-layered FGMs using XFEM, Comput Mech (2013) 1-16.

[208] O. Bacarreza, M. H. Aliabadi, A novel methodology for fatigue delamination growth analysis of composites, Vol. 488-489, 2012, pp. 763-766.

[209] ASTM Standard D5528-01, 2007, Standard test method for mode I interlaminar fracture toughness of unidirectional fiber-reinforced polymer matrix composites, ASTM International, West Conshohocken, PA, USA (2007).

[210] ASTM Standard D 6671/ D 6671M-06, 2006, Standard test method for mixed mode I-mode II interlaminar fracture thoughness of unidirectional fiber reinforced polymer matrix composites, ASTM International, West Conshohocken, PA, USA (2006).

[211] R. Khan, Mode I fatigue delamination growth in composites, Phd thesis, Delft University of Technology, to be published. 